Grant-in-Aid for Scientific Research (S)

Real Estate Markets, Financial Crisis, and Economic Growth

: An Integrated Economic Approach

Working Paper Series No.71

Inflation Rates Are Very Different When Housing Rents Are Accurately Measured

\author{
Brent W. Ambrose \\ N. Edward Coulson \\ and \\ J iro Yoshida
}

October, 2017

HIT-REFINED PROJ ECT

Institute of Economic Research, Hitotsubashi University

Naka 2-1, Kunitachi-city, Tokyo 186-8603, J APAN

Tel: +81-42-580-9145

E-mail: hit-refined-sec @ier.hit-u.ac.jp

http://www.ier.hit-u.ac.jp/hit-refined/ 


\title{
Inflation Rates Are Very Different When Housing Rents Are Accurately Measured $]^{*}$
}

\author{
Brent W. Ambrosef; N. Edward Coulson
}

October 5, 2017

\begin{abstract}
One of the largest components of official price indexes is housing services, which account for 16 percent to 41 percent of major price indexes in the United States (e.g., Consumer Price Index). This paper demonstrates that the current measure of housing rents does not accurately track the actual inflation rate of housing rents. We construct an alternative quality-adjusted measure of housing rents that is based on a monthly statistic of landlord net rental income. Compared with our modified inflation rate, the official rate was overestimated by 1.4 percent to 3.4 percent annually during the Great Recession but underestimated by 0.3 percent to 0.7 percent annually during the current expansionary period after the recession. We further demonstrate significant impacts of our improved measurement of inflation rates on the cost of living adjustment to Social Security and real gross domestic product. These impacts persist for a long term because the modified price indexes are integrated of order one whereas the official indexes are trend stationary.
\end{abstract}

JEL classification: E01, E31, R31, H55.

Keywords: measurement error, economic statistics, owners' equivalent rent, Consumer Price Index, Personal Consumption Expenditures, National Income and Product Accounts.

${ }^{*}$ We thank Tsutomu Watanabe, Febrio Kacaribu, and seminar participants at NBER East Asian Seminar on Economics, Hitotsubashi University, Cornell University, National University of Singapore, and MIT for their helpful comments and suggestions. We also thank Mark Thibodeau for research assistance and the Penn State Institute for Real Estate Studies and JSPS (KAKEN Grant \#25220502) for financial support.

${ }^{\dagger}$ Institute for Real Estate Studies and the Department of Risk Management, Smeal College of Business, The Pennsylvania State University, University Park, PA 16802-3306, bwa10@psu.edu.

${ }^{\ddagger}$ Merage School of Business, University of California, Irvine, CA 92697-3125, n.edward.coulson@gmail.com.

$\S$ Department of Risk Management, Smeal College of Business, The Pennsylvania State University, 368 Business Building, University Park, PA 16802, jiro@psu.edu. 


\section{Introduction}

Official price indexes, such as the Bureau of Labor Statistics' (BLS) Consumer Price Index (CPI) and the Bureau of Economic Analysis' (BEA) Personal Consumption Expenditure (PCE) Price Index in the national income and product accounts (NIPAs), are susceptible to measurement errors (Hausman, 2003). A number of academic researchers and government commissions have pointed out various issues and have helped improve the official price indexes (see the surveys by Hausman, 2003; Lebow and Rudd, 2003; Reinsdorf and Triplett, 2009). The major issues identified as problematic include substitution effects and aggregation methods (e.g., Diewert, 1976; Manser and McDonald, 1988; Aizcorbe and Jackman, 1993 ; Shapiro and Wilcox, 1996), quality changes in existing goods (e.g., Moulton and Moses, 1997; Shapiro and Wilcox, 1996; Lebow and Rudd, 2003), sample representativeness and introduction of new goods (e.g., Gordon et al., 1993; Griliches and Cockburn, 1994; Shapiro and Wilcox, 1996), shifts in shopping patterns (e.g., Reinsdorf, 1993; Shapiro and Wilcox, 1996), relative importance weights (e.g., Lebow and Rudd, 2003), and including owner-occupied housing in the CPI (e.g., Diewert, 2009) 1

The impact of measurement errors can be enormous because these price indexes are the basis of a wide range of economic statistics, contracts, public policy programs, asset prices, and most importantly, corporate and consumer decision making. For example, real gross domestic product and productivity growth are estimated by deflating nominal values by price indexes. A number of contracts and public programs are indexed to CPI; e.g., Treasury Inflation Protected Securities (TIPS), lease contracts, labor contracts, social security, and income tax brackets. Monetary policy is often evaluated on the basis of measured inflation rates. Finally, the expected future inflation rate is an important component of the discount rate and thus, it critically affects consumption and investment.

We demonstrate a new source of bias that is caused by measurement errors in housing

\footnotetext{
${ }^{1}$ More recently, a stochastic nature of measurement errors is studied (e.g., Svensson and Woodford, 2004 Handbury et al., 2015, Aoki, 2006).
} 
rents. Since changes in housing rents comprise a significant portion of price inflation and given the importance of housing to the economy, we focus on how differences in measuring the housing component affect the construction of the CPI and PCE price indexes. We then demonstrate that current estimates of housing rent inflation, which understate the variation in the actual rent inflation with significant lags, can have material and economically significant effects on a variety of economic policies and decisions.

To confirm the role of housing in overall measures of inflation, Figure 1 and Table 1 show the relative importance of housing in the CPI and PCE indexes between 1997 and 2016. In 2015, the shelter price (or housing component) accounted for 32.8 percent of the CPI and 41.4 percent of the core CPI, excluding food and energy. Housing services, which are the PCE equivalent of the CPI shelter component, accounted for 15.6 percent of all items and 17.5 percent of the core items ${ }^{2}$ Breaking down the housing components, the CPI and PCE include the consumption of housing services by persons who own the housing that they occupy (i.e., the imputed rent for owner-occupied housing) as well as by those who rent their housing. Table 2 shows that owners' equivalent rent comprises 73.9 percent of CPI shelter while the rent of primary residence accounts for 23.6 percent. These relative weights of the housing components are similar in the PCE housing services.

Since housing is an integral component to the CPI and PCE inflation indexes, it is thus directly linked to numerous academic studies and public policies. As a result, even small changes in the housing component of inflation can have impacts on such diverse areas as consumer welfare calculations (e.g., Bajari et al., 2005), macro-economic studies of possible price bubbles (e.g., McCarthy and Peach, 2004, 2010; Himmelberg et al., 2005, Campbell and Shiller, 1988; Brunnermeier and Julliard, 2008; Verbrugge, 2008; Campbell et al., 2009; Summers, 1981), interest rates (e.g., Taylor, 1993a, b; Clarida et al., 2002, 2000; Ambrose

${ }^{2}$ The variation in these weights mainly stems from the difference in the coverage of goods and services. For example, the PCE includes goods and services purchased on behalf of households (e.g., medical care premium payments made by the employers and by the government) whereas the CPI reflects only out-ofpocket expenditures of all urban households. The PCE also includes the imputed cost of financial services that do not involve out-of-pocket expenditures. 
et al., 2015a), tax policies (e.g., Poterba, 1984), tenure choice decisions (e.g., Sinai and Souleles, 2005; Halket and Custoza, 2015), housing price index construction (e.g., Gatzlaff and Haurin, 1997; Clapp et al., 1991; Clapp and Giaccotto, 1998; McMillen and Thorsnes, 2006; Meese and Wallace, 1997; Shiller, 1991), and housing rental rates (e.g., Genesove, 2003; Eichholtz et al., 2012). Cecchetti (2007) notes the increased importance of inflation targeting by central banks and notes that "The big question for inflation measurement is how to handle housing."

The BLS estimates rental cost inputs for the CPI shelter and PCE housing services components using repeated surveys of existing tenants. Thus, the CPI and PCE price index mainly capture changes in rents for existing tenants and miss rental updates that result upon tenant turnover ${ }^{3}$ As Ambrose et al. (2015b) discuss at length, this sampling method introduces several biases in the rental cost estimate. First, the BLS index tends to underestimate rent appreciation during expansionary periods and overestimate it during recessionary periods because it mainly reflects the renewal rent for existing tenants.4 In addition, the underrepresentation of new leases is exacerbated during recessions when the tenant turnover increases $5^{5}$ As a result, the BLS index did not exhibit significant depreciation

\footnotetext{
${ }^{3}$ To illustrate the impact of these problems, consider the following hypothetical case of two identical residential rental units in a market where rent appreciates annually by 10 percent over four years until it depreciates 10 percent in the fifth year. In Unit A, tenant turnover occurs every year on the first day of January, but the tenants in the third and fifth years do not respond to the January and July CPI renter survey. As a result, the BLS observes rent appreciation only once between July of the first year and January of the second year when consecutive tenants respond to the survey. The recorded inflation rate is zero percent for the intra-lease period between January and July when tenants respond. No other information is recorded. In contrast, assume that a long-term tenant occupies Unit B and responds to all surveys. Her one-year lease contract is renewed each February 1st. Thus, she reports no rent inflation between July and January but a moderate rent inflation (5 percent) between January and July due to moderate rent increases. Thus in this hypothetical, new tenants in Unit A are underrepresented in the BLS sample while the sitting tenant in Unit B is overrepresented. Furthermore, the sample includes many observations with no growth but omitts most of large rent changes.

${ }^{4}$ Crone et al. (2010) note that the omission of rent changes due to tenant turnover likely biased downward the CPI by 1.4 percent per year between 1940 to 1985. Lane et al. (1988) and Gordon and vanGoethem (2007) also provide evidence supporting the downward bias. Gallin and Verbrugge (2007) discuss improvements to the BLS methods for measuring inflation. Futhermore, in defense of the CPI, Verbrugge and Poole (2010) argue that differences in local rental patterns within cities account for much of the differential between observed rent inflation and the shelter component (the Owners' Equivalent Rent, or OER).

${ }^{5}$ Even if rents on long-term lease renewals do not appreciate as much as the marginal rents on new lease contracts, the OER should reflect changes in marginal rents. The rational is that the long-term rents were set in the past based on expectations. However, realized rent may differ from past expectations as marginal
} 
in recent recessions $5^{6}$ Second, as noted by Verbrugge (2008), the BLS index construction method introduces additional smoothing effects by averaging the rent for each survey month and then calculating the six-month average growth rate on a rolling basis (i.e., January-July, February-August, etc.). Third, the BLS rent index lags contemporaneous rent measures. For example, if all leases are annual, then only $1 / 12^{\text {th }}$ of the BLS sample will reflect market conditions with some observations reflecting economic environments that are nearly a year old. Thus, the BLS index only gradually incorporates market information, lagging the contemporaneous market rent measure by approximately one year. ${ }^{7}$

To overcome these biases, Ambrose et al. (2015b) propose a new rental index based on repeated unit-specific rental contracts (the Repeat Rent Index, or RRI). The RRI is a quality-adjusted rent index that measures the marginal rent for newly-signed lease contracts with new tenants. In the RRI data, the survey omission issue is absent because they are based on lease payments to landlords. The RRI exhibits large rent depreciation during the Great Recession, greater volatility than the BLS index, and Granger causality with the BLS index. Ambrose et al. (2015b) confirm that these differences do not stem from differences in sample characteristics. Unfortunately, one shortcoming of the RRI is that it ends in 2010, limiting its use for post Great Recession analysis.

To rectify the truncation of the RRI series, we propose a new method for estimating inflation in housing service prices. Our new series, called the Net Rent Index (NRI) is based on the Moody's/RCA Commercial Property Price Index (CPPI) for apartments..$^{8}$ The CPPI is a quality-adjusted repeat sale index. By multiplying the monthly CPPI by the monthly average multifamily capitalization rate (i.e., income yield), we obtain a consistent monthly

rents reflect current period expectations. Thus, current marginal rents more accuractely indicate the costs of housing.

${ }^{6}$ Although Crone et al. (2010) note that these problems have been partly addressed, Ambrose et al. (2015b) demonstrate that significant biases still exist in the 2000's. In addition, Ozimek (2014) demonstrates a similar bias using market rents on single-family rentals in the Baltimore/Washington, D.C. area while Shimizu et al. (2010) find a similar bias in the Japanese CPI rents.

'See Ambrose et al. (2015b) for analysis of the lag structure.

8 For detailed description of the index, see https://www.rcanalytics.com/public/pdf/MOODYSCPPI_ FactSheet.pdf 
index of net rental income that is based on arm's length market transactions and reflects cash flows from both new and existing leases. After converting the data between 2002 and 2010 to a quarterly series, we validate that the NRI tracks the RRI with a high degree of precision - having a correlation of 0.858 in year-over-year growth rates. In contrast to the CPI rental component and consistent with the RRI, the NRI reveals that rental rates fell consistently during the Great Recession and then rebounded with double-digit yearly increases after 2010. By construction, the NRI is fully consistent with the recent property price boom and bust $9^{9}$

Having verified that the new NRI captures important characteristics of the housing market that are missed by the CPI rental component, we next demonstrate that actual inflation rates may have varied substantially from reported rates. To do so, we replace the CPI/PCE rent index with the NRI-based rent measures. Specifically, we use the NRI and construct additional two derivative rent measures: Gross Rent Index and Marginal Rent Index. We then substitute the former for the rental price of tenant-occupied housing and the latter for the imputed rental price of owner-occupied housing. We use time-varying importance weights for these items to construct four modified chain-type price indexes: all-item CPI, core CPI, all-item PCE, and core PCE.

Our analysis reveals that significant biases exist in the official inflation measures especially since 2007:IV when the Great Recession started. The official all-item inflation rates were 1.4 percent to 1.5 percent during the recession whereas the modified inflation rates were -1.1 percent to -0.04 percent. Similarly, the official core inflation rates were 1.7 percent to 2.1percent whereas the modified rates were -1.4 percent to 0.1 percent. The upward bias ranges from 1.4 percent to 3.4 percent per year. In contrast, during the expansionary period since 2009:III, the official inflation rates are significantly lower than the modified rates. The official all-item inflation rates are 1.5 percent to 1.6 percent whereas the modified rates are

\footnotetext{
${ }^{9}$ The apartment property price index appreciated by 79.5 percent during the housing boom in the 2000's (2001:I-2007:IV). During the same period, the NRI appreciated by 32.2 percent, and the capitalization rate decreased by 26.0 percent. A similar result is obtained with other data (e.g., The CoStar multifamily index).
} 
1.7 percent to 2.2 percent. Similarly, the official core inflation rates are 1.5 percent to 1.7 percent whereas the modified rates are 1.8 percent to 2.4 percent. The downward bias ranges from 0.3 percent to 0.7 percent per year. Thus, measurement errors in housing rents cause biases in both directions. The fundamental issues related to these biases are underestimated volatility and significant lags in the official rent measure.

In order to assess the long-run implication of the modification, we examine the time-series property of the price indexes. For example, if an index has a unit root, then an inflation shock will have a permanent impact on the price level. However, if the modified index is cointegrated with the official index, then the modification will make a small difference in the long-run. The Phillips-Perron unit root test shows that the original price indexes are trend stationary whereas the modified indexes are integrated of order one, or $I(1)$. The trend stationary price index is consistent with the idea of the Great Moderation (e.g., Stock and Watson, 2002; Bernanke, 2012; Clark, 2009). However, our modification makes the price index $I(1)$ as Nelson and Plosser (1982) find using the data before 1980's. Thus, the measurement of housing rents significantly impacts how we characterize the economy. This test result also indicates that our modification makes a long-term economic impact.

We further present two example applications that demonstrate the economic significance of the bias: Social Security benefits and real gross domestic product. The first application considers an impact on the Social Security benefits, which are indexed to the CPI inflation rate (i.e., cost-of-living adjustments or COLAs). Following the financial crisis, the COLAs based on our modified CPI would have been 0.8 percent per year higher. Thus, for an individual in 2016 who had been a beneficiary for 5 years, cumulative benefits using the modified COLAs would have been 6.3 percent higher. In dollar terms, the monthly benefit for a 70-year old individual who retires in 2016 would be $\$ 178$ greater and the difference in total Social Security system benefit payments would be approximately $\$ 35.3$ billion.

The second application considers an impact on the calculation of real gross domestic product (GDP). Our modification to the PCE price deflator has a direct effect on the real 
PCE as well as real GDP since the U.S. GDP is calculated by adding final expenditures. If our modified deflator had been used, the decrease in real GDP during the Great Recession would have been more moderately estimated: -7.2 percent per annum in 2008:IV as compared with the official figure of -8.5 percent. In contrast, the average real economic growth rate would have been smaller after the recession: 1.9 percent per annum between 2009:III and 2016:I as compared with the official figure of 2.1 percent. Thus, once measurement errors in housing rents are corrected, the U.S. economy has been growing at 1.9 percent per year following the Great Recession, but the core inflation rate has been 2.4 percent. Our analysis suggests that the U.S. may be experiencing a 'stagflation' period.

Our paper is organized as follows. In the next section, we discuss the variety of data sets used to construct the accurate housing rent index. Section 3 describes how we construct and validate our new rent indexes and modify the CPI and PCE price indexes. Section 4 then compares the official price indexes with our modified price indexes. In section 5 , we turn to a few applications to demonstrate the economic significance of accurately measuring housing rent inflation. Finally, section 6 concludes.

\section{Data}

In order to illustrate the effect of different rental rates on inflation calculations, we assemble data from a variety of sources. First, we utilize the repeat rent index (RRI) as developed in Ambrose et al. (2015b). The RRI is based on residential rent transactions reported by Experian RentBureau for the period from January 1998 to December 2010 10 Ambrose et al. (2015b) document that the RRI is more volatile than the BLS rental data that are used in the CPI and PCE price series. They also show that the BLS lags the RRI indexes suggesting that the BLS rental series do not track current market conditions. In a follow-up study focused on optimal monetary policy, Ambrose et al. (2015a) recalculate the

\footnotetext{
10 Ambrose and Diop (2014) provide a more complete description of the RentBureau data.
} 
CPI and PCE indexes by substituting the RRI index for the housing component 11 They demonstrate that the RRI-based price indexes differ substantially from the original CPI and PCE indexes. Their analysis also confirms that this difference is not caused by the underlying sample characteristics such as geographical weights.

Table 3 demonstrates that the BLS rent index (and equivalently, PCE and CPI rent indexes) lags the RRI as Ambrose et al. (2015b) point out. The table shows the F-statistic and the adjusted R-squared of a regression: $g_{P C E, t}=\alpha+\beta g_{R R I, t-n}+\varepsilon$, where $g_{P C E, t}$ is the percentage change from year ago in the PCE rent for tenant-occupied housing, $g_{R R I, t-n}$ is the n-quarter lagged percentage change from year ago in the RRI, and $\varepsilon$ is the error term. Both statistics are largest when the RRI is lagged by 5 quarters. The implied correlation coefficient between these two indexes is 0.94 when the 5-quarter lagged RRI is used.

While the RRI developed by Ambrose et al. (2015b) has distinct advantages in measuring housing rent inflation, it unfortunately suffers from a serious drawback - it is unavailable after December 2010. In order to overcome this shortcoming, we assemble a new database comprising repeat property transactions to create a new net rent index. We use the Moody's/RCA Commercial Property Price Index (CPPI) for apartments as the backbone for constructing our net rent index. The CPPI is a monthly repeat sale index starting in December 2000 and is based on the Real Capital Analytics commercial real estate transaction data, which is one of the most comprehensive datasets covering investment grade rental housing. This index comprises transactions from domestic and foreign institutional and private investors but excludes non-arm's length and other non-standard transactions. The index covers 20 states and 34 metropolitan markets. For a property to be included in the index, RCA requires that the first transaction in the repeat-sale pair be greater than $\$ 2.5$ million in 2010 constant value and the prices are not adjusted for routine capital expenditures. The properties in the RCA sample are similar to the properties underlying the RRI constructed in Ambrose et al.

\footnotetext{
${ }^{11}$ In addition, Ozimek (2014) finds a similar pattern in the Baltimore-Washington, D.C. single-family rental market; and single-family data from CoreLogic also produces a similar result.
} 
(2015b) in that they tend to be larger complexes ${ }^{12}$ Furthermore, the CPPI is publicly available and produced on a timely basis making it invaluable for constructing updated measures of housing rental prices. By multiplying the CPPI by average capitalization (or cap) rates for apartments, we construct the NRI, a quality adjusted average net rent index for both new and existing tenants. The NRI also represents so-called net operating incomes (NOI) for apartment investors 13 Net rental income equals gross rental income less property level operating expenses such as property taxes, property insurance, and maintenance costs. The advantage of the NRI is that it is based on arm's length market transactions, reflects the cash flow from new and existing leases, comprises a consistent rent type (net rent), and is updated monthly. ${ }^{14}$ Figure 2 shows the CPPI and corresponding cap rates.

To validate our NRI as a measure of the rental market, we compare the NRI, the 5quarter lead PCE Rent, and the RRI in Figure 3. The figure clearly shows that these three indexes reflect the common market dynamics although they exhibit significantly different volatility. Table 4 presents the pairwise correlation coefficient between year-over-year percentage changes in alternative rent indexes based on 33 quarters between 2002:I-2010:I. The NRI reflects the average net rent for both new and existing tenants. In contrast, the RRI and the PCE rent reflect gross rents for new tenants and existing tenants, respectively. The NRI is highly correlated with both the RRI (The coefficient is 0.858.) and the 5-quarter lead PCE rent (The coefficient is 0.884.). The coefficient between the RRI and the 5-quarter lead PCE Rent is even lager (0.950). However, the contemporaneous PCE Rent exhibits small correlation coefficients with other indexes. This result confirms the discussion by Ambrose et al. (2015b) that the BLS rent index lags the contemporaneous market rent by approximately one year because of its sampling and index construction method. The result shown in

\footnotetext{
${ }^{12}$ For example, in the RCA Cap Rate Sample, which is the source data for CPPI repeat sale index, the average number of transactions per month is 375, the average property size is 167 units, the average property value is $\$ 14.9$ million, and the average price per unit is $\$ 90,600$. These statistics are comparable to the descriptive statistics for the data underlying the RRI as reported in Ambrose et al. (2015b) and Ambrose and Diop (2014).

${ }^{13}$ Since cap rate is defined as NOI divided by property price, we can recover NOI by multiplying property price by cap rate.

${ }^{14}$ We feel that these advantages outweigh any negative aspects associated with its simplistic construction.
} 
this table indicates that the NRI, the RRI, and the lead PCE rent reflect the same dynamics of rental housing markets. The key difference between these three indexes is volatility.

Table 5 presents the mean and standard deviation of quarterly percentage changes in alternative rent indexes during 36 quarters between 2001:II and 2010:I. The PCE rent is least volatile with the quarterly standard deviation of 0.322 percent. This is because the index construction method has several smoothing effects (Verbrugge, 2008). In particular, the PCE rent reflects mostly renewal rents for the same existing tenants due to the BLS survey design. Thus, the PCE rent represents an infra-marginal rent in the rental market. In contrast, the RRI is more volatile than the PCE rent (The quarterly standard deviation is 1.394 percent.). The RRI reflects the rent change that landlords make (either upward or downward) at the time of tenant change. These changes are usually larger than the changes in renewal rents for the existing tenants. Thus, the RRI represents the marginal rent. The NRI is more volatile than the RRI (The quarterly standard deviation is 3.169 percent.) although the NRI reflects rents for both the existing and new tenants. This large volatility of net rent is due to operating leverage. Since net rents are equivalent to gross rents less operating expenses such as property taxes, which are largely fixed and not affected by the short-term rental market condition, net rents become more volatile than gross rents.

\section{Construction of the Modified Price Indexes}

The price of housing services is mainly composed of two elements: the rental price of tenant-occupied housing and the imputed rental price of owner-occupied housing $[5$ Table 2 shows the weight of each element in the CPI and the PCE price. For both price indexes, approximately a quarter is for tenant-occupied housing and three quarters are for owneroccupied housing. Since our goal is to estimate the modified price indexes that reflect housing costs more accurately, we take the following four steps.

\footnotetext{
${ }^{15}$ In CPI, the former is termed the rent of primary residence and the latter is termed owners' equivalent rent.
} 
First, we note that the average gross rent for both new and existing tenants should be used for the rent of tenant-occupied housing. The NRI reflects rents for both new and existing tenants but excludes operating expenses. Alternatively, a mixture of the RRI and the PCE rent is also relevant because the former reflects the gross rent for new tenants and the latter mainly reflects the gross rent for existing tenants. The proportions of new and existing tenants are estimated by two studies. First, Wheaton and Nechayev (2009) estimate that the ratio of the number of new lease contracts to the number of existing renters is 29.8 percent in 2001 (There were 10,272,000 new contracts and 34,417,000 renters at the end of the year.) Second, Crone et al. (2010) estimate turnover rate (the ratio of movers to the occupied rental units) by using Vacancy Survey, American Housing Survey, Census, and Residential Construction Survey. The average turnover rate is 34.4 percent between 1970 and 2002. Thus, we estimate the average rent for tenant-occupied housing by using the estimated proportion of new leases. We conservatively assume that the proportion of new leases is 0.3. We calculate the quarterly percentage change in the average rent by the following equation:

$$
g_{\text {avg }, t} \equiv 0.7 \times g_{p c e, t+5}+0.3 \times g_{r r i, t},
$$

where $g_{a v g, t}, g_{p c e, t}$, and $g_{r r i, t}$ denote the percentage change during quarter $t$ in the average rent, the PCE rent, and the RRI, respectively. The data period is between 2000:I and 2010:I. By using the quarterly percentage change, we also calculate the index level and the percentage change from year ago.

Second, we construct the Gross Rent Index by matching the mean and standard deviation of NRI with those of the Average Rent Index. Table 5 shows the matched mean and standard deviation for the Average and Gross Rent Indexes. The Gross Rent Index is extended until 2016:I by applying the same conversion equation to the NRI. Figure 5 depicts the index level and percentage change from year ago for these two indexes. A good fit of these two indexes can be visually confirmed. 
Third, we note that the economic concept of owners' equivalent rent (i.e., the imputed rent of owner-occupied housing) is an opportunity cost for a homeowner, who can potentially rent out a house or move to rental housing. In a housing market equilibrium, the opportunity cost of owning a house equals the marginal rent for a new tenant in the rental market (e.g., see Summers, 1981; Poterba, 1984; Topel and Rosen, 1988; Mankiw and Weil, 1989). In particular, the opportunity cost includes the cost of capital, the expected net depreciation of property value, and operating expenses such as property tax and maintenance costs. Thus, a marginal gross rent measure should be used for this element. Although the RRI is best suited for this purpose, as we discuss above, the index cannot be extended after 2010. Thus, we construct the Marginal Rent Index by matching the mean and standard deviation of NRI with those of the RRI. Table 5 shows the matched mean and standard deviation for the RRI and the Marginal Rent Index. The Marginal Rent Index is extended until 2016:I by applying the same conversion equation to the NRI. On the basis of Figure 6 that depicts these two indexes, we confirm a good fit of these two indexes.

Fourth, we derive the modified inflation rate by replacing the rental price of tenant- and owner-occupied housing with the Gross and Marginal Rent Indexes, respectively. Specifically, we compute:

$$
i_{m o d, t} \equiv i_{o r i, t}-w_{h, t} g_{h, t}+w_{r o h, t} g_{m r i, t}+\left(w_{h, t}-w_{r o h, t}\right) g_{g r i, t},
$$

where $i_{\text {mod, } t}$ and $i_{\text {ori,t }}$ are the modified and original quarterly inflation rates, respectively. The inflation measure can be based on all or core items. We let $w_{h, t}$ and $w_{r o h, t}$ denote the relative weight for housing (shelter) and rental of owner-occupied housing (owners' equivalent rent), respectively. These weights change every quarter ${ }^{16}$ We let $g_{h, t}, g_{m r i, t}$, and $g_{g r i, t}$ denote

\footnotetext{
16 The relative importance for CPI is available at: http://www.bls.gov/cpi/cpiriar.htm. For the PCE, we follow U.S. Bureau of Economic Analysis (2012) and use current-dollar PCE expenditures as the relative importance weights. We confirm that these weights give accurate aggregation results by computing the weighted average of quarterly inflation rates for goods and services between 2000 and 2010 . The mean difference in quarterly inflation rate between the weighted average and the official chain-type price index is 0.003 percent. The weight in 2016 is extrapolated from 2015 for CPI and based on the first-quarter data for PCE.
} 
quarterly percentage change in the original housing service price, the Marginal Rent Index, and the Gross Rent Index, respectively. We further compute the price index level and percentage change from year ago.

Since we simply replace the official rent index with our rent indexes, one may suspect that we fail to take into account substitution effects. In other words, when housing services become relatively expensive, housing services may become less important in a price index because consumers may switch away from housing services to relatively less expensive goods and services. However, substitution effects are not a serious concern to our modified index for three reasons. First, we use time-varying importance weights to construct a chained price index. Thus, substitution effects are incorporated in our index. Second, the elasticity of substitution between housing services and other goods is very small. The estimated elasticity of substitution is between 0.4 and 0.9 (Davidoff and Yoshida, 2013), and the estimated price elasticity of housing services is between -0.8 and -0.3 (Mayo, 1981; Harmon, 1988; Ermisch et al., 1996; Green and Malpezzi, 2003). Thus, a change in relative prices does not make a large impact on housing services consumption. Third, as Hausman (2003) emphasizes, substitution effects are a second-order effect whereas measurement errors in housing rents have the first-order effect.

Our strategy effectively extrapolates the relation between indexes before the Great Recession into the period after the recession. Thus, this strategy depends on the stability of relations between indexes. To validate the relevance of this strategy, we test the structural break in the relation between indexes before and after the Great Recession. Since the 5quarter lead PCE and the NRI are available throughout the entire sample period, we examine the relation between these two indexes. As Figure 7 depicts, quarterly percentage changes in these two indexes are positively correlated both before and after the recession. We formally test the structural break by the Chow Test. The regression equation is:

$$
g_{p c e, t+5}=\beta_{0}+\beta_{1} g_{n r i, t}+\beta_{2} D+\beta_{3}\left(D \times g_{n r i, t}\right)+\varepsilon
$$


where $D$ denotes a dummy variable that takes the value of one after the Great Recession (2009:III-2014:IV). Rejecting a hypothesis $\beta_{3}=0$ is an indication of a structural break in the relation between these two indexes. The data period is between 2001:II-2014:IV but excludes an NBER recession period that corresponds to the Great Recession (between 2007:IV and 2009:II). Table 6 shows the test result based on the Newey-West heteroskedasticity and autocorrelation corrected standard errors. The estimated $\beta_{3}$ is not statistically significant at any conventional level. Thus, we conclude that there is no structural break in the relation between the NRI and the 5-quarter lead PCE before and after the Great Recession.

Another concern is that vacancy rates might distort the NRI. The NRI measures the landlord net income from the occupied units. Since the vacancy rates change over the business cycle, the NRI reflects changes in both net rental rate and vacancy rates. Panel (a) of Figure 4 depicts the quarterly percentage change in NRI and the national rental vacancy rate published by the U.S. Bureau of the Census. The NRI is negatively correlated with vacancy rates. In particular, vacancy rates increased from 9.6 percent to 11.1 percent during the Great Recession when the NRI plunged from 9.0 percent to -25.9 percent. However, the effect of vacancy rates on NRI is not large for two reasons. First, there is no lead-lag relation between NRI and vacancy rates. Thus, the effect of vacancy rates is mainly on the volatility of NRI growth rates. Second, the variation in occupancy rates (i.e., 1- vacancy rates) is not large during the sample period; the range is between 88.9 percent and 93.2 percent. To confirm that the effect of vacancy rates is small, we construct the Vacancy-Adjusted Net Rent Index by dividing NRI by 1 minus vacancy rates. Panel (b) of Figure 4 demonstrates that the difference is negligible. Table 7 shows the summary statistics of these two indexes and the test result about equal means and variance. As we expect, the Vacancy-Adjusted NRI is less volatile only by a small margin. We do not reject the null hypotheses of equal means or equal variance. Furthermore, because the correlation coefficient is 0.992 between quarterly changes in NRI and Vacancy-Adjusted NRI, these two indexes are effectively identical time series (Table 8). Thus, vacancy rates make virtually no impact on Net Rent Index. 


\section{Result}

We now turn to the primary focus of our study - demonstrating that actual inflation rate would vary substantially from the reported series if one were to correct for the problems associated with the BLS rental series. Figures 8-11 depict the original and modified price indexes. Each figure shows the index level (panel (a)), the percentage change from year ago (panel (b)), and the difference between these two rates (panel (c)). Tables in Appendices A - C present the quarterly estimated values.

Figure 8 shows the modified all-item CPI. In 2005 at the height of the housing boom, the modified CPI increased faster than the original CPI. However, generally in the 2000's until the end of the Great Recession, the modified CPI increased more slowly than the original CPI. In particular, the modified index exhibits sharp deflation as large as 5 percent during the Great Recession. In contrast, in the current expansionary period starting in 2009:III, the modified CPI started to increase faster than the original CPI approximately by 0.5 percent per year. Figure 9 also exhibits a similar result for the all-item PCE although the difference is more moderate because of the smaller importance of housing in the price index. In particular, inflation rates are largely identical until the beginning of the Great Recession. However, we observe that the modified index deviates negatively during the Great Recession and positively during the current expansionary period after the recession. The most severe deflation rate was 2.7 percent. The difference between two inflation measures is approximately 0.3 percent in the current expansionary period.

Figures 10 and 11 exhibit similar but sharper contrasts for core inflation measures than for the all-item measures. Although the original core inflation measures do not exhibit any deflation since 2001, the modified core measures show sharp deflation during the Great Recession. The deflation rate reached 3 percent for the core CPI and 1 percent for the core PCE price; the rate difference was 5 percent for the core CPI and more than 2 percent for the core PCE price in this deflationary period. In the current expansionary period, the modified core inflation measures are greater than the original core measures by approximately 0.5 
percent.

Table 9 summarizes the annualized average quarterly inflation rate for four different time periods defined by the NBER recession status while table 10 presents the difference in inflation rates between the original and modified inflation measures. During the expansionary period between 2002:I and 2007:III, the average inflation rate was 2.4 percent to 2.8 percent by the original all-item measures and 2.2 percent to 2.5 percent by the modified all-item measures. Thus, there was a 0.2 percent to 0.3 percent upward bias during this expansionary period. However, the bias became significantly larger during the Great Recession. The original all-item inflation rates were 1.4 percent to 1.5 percent but the modified all-item inflation rate was -1.1 percent for CPI and -0.04 percent for PCE. The upward bias was 2.7 percent for CPI and 1.4 percent for PCE. This bias was even greater for core measures: 3.4 percent for core CPI and 1.6 percent for core PCE. The official inflation measures did not reflect large deflation in housing rents. In contrast, during the expansionary period after the Great Recession, the direction of bias is reversed; there was a 0.5-0.7 percent downward bias in the all-item measures and a 0.3 percent downward bias in the core measures. During this recovery period, the official measures did not reflect large inflation in housing rents. Thus, measurement errors in housing rents can cause biases in both directions. The major issues are underestimated volatility and significant lags in the official rent measure.

The positive difference (i.e., greater inflation rates by the modified measures) in the current expansionary period may give us a clue to resolving a puzzle regarding the unconventional monetary policy after the Great Recession. The puzzle is that "official" inflation rates did not respond to monetary policy as many policymakers expected despite its unprecedented scale ${ }^{17}$ However, we show that inflation rates exhibited greater responses when housing rents are accurately measured.

In order to assess the long-run implication of the modification, we examine the time-series property of the price indexes by testing whether they are diffusions or trend stationary and

\footnotetext{
${ }^{17}$ The Federal Reserve started the Large Scale Asset Purchases (LSAPs) in December 2008 (so-called QE1) and continued them until November 2014 (so-called QE3).
} 
whether the modified index is cointegrated with the original index. For example, if an index has a unit root, then an inflation shock will have a permanent impact on the price level. However, if an index is trend stationary, then the effect of an inflation shock is temporary. If the modified and original indexes are diffusions and the modified index is cointegrated with the original index, then the modification will make a small difference in the long-run.

Table 11 shows the results of the Phillips-Perron unit root test. The Augmented DickeyFuller test also provides qualitatively the same result. The reported numbers are the MacKinnon approximate p-value of failing to reject the null hypothesis that the variable contains a unit root. A consistent result is that the modified indexes have unit roots whereas the original indexes do not. For example, the p-value for the original core CPI is 0.00 for any number of lags whereas the p-value for the modified core CPI is between 0.97 and 1.00. The p-value for the first difference is less than or equal to 0.06 for all indexes. Thus, the original

price indexes are trend stationary whereas the modified indexes are integrated of order one, or $I(1)$. This obviously means that the modified index is not cointegrated with the original index. The price index is often considered $I(1)$ based on the data before 1980's (e.g., Nelson and Plosser, 1982). However, our finding suggests that the price index has become trend stationary in recent years, a change which may be associated with the Great Moderation (e.g., Stock and Watson, 2002; Bernanke, 2012, Clark, 2009). This finding has an important implication for the role of our modification. When we measure the price level by the modified index, an inflation shock has a permanent effect on the price level. The difference between the original and the modified index is also persistent. Thus, the sample applications that we demonstrate in the next section are important in the long run.

\section{Applications}

We now turn to two example applications that demonstrate the economic significance of the differences between the original and modified inflation measures. Our first application 
considers the impact of the modification to CPI on the Social Security Administration's annual cost-of-living adjustments (COLAs). Social Security benefits are indexed to inflation in order to protect beneficiaries from the loss in purchasing power associated with rising prices. Thus, mis-measuring inflation can have a profound affect on the segment of the population most at risk to loss of purchasing power (the elderly on living on fixed-incomes.) Our second application considers how the change in the PCE price index can impact calculations of the real Gross Domestic Product (GDP). Since economic growth and fluctuations are analyzed by real GDP, inaccurate estimates of real GDP can distort the fundamental macroeconomic analysis.

\subsection{Cost-Of-Living Adjustments}

As noted in the introduction, a variety of contracts and programs are linked to changes in the CPI. As a result, differences in measured inflation between the BLS CPI and our NRI-based CPI can have profound effects on these contracts and programs. For example, the CPI-W is used as the index for yearly COLAs for determining Social Security (OASDI) and Supplemental Security Income (SSI) benefits ${ }^{18}$ Burdick and Fisher (2007) provide an overview of the issues associated with COLA calculations and discuss the controversy surrounding the use of various CPIs in determining the yearly adjustments. Furthermore, Burdick and Fisher (2007) and Goda et al. (2011) note that the use of the CPI-W in current COLA calculations significantly mis-measures actual inflation experienced by the elderly due to the differences in medical expenses, housing costs, and shopping habits of the elderly versus the general population. For example, Goda et al. (2011) suggest that the net-of-medicalspending benefit for a man born in 1918 declined by approximately 20 percent between 1983 and 2007.

\footnotetext{
${ }^{18}$ Since 1975, Social Security and SSI benefits are automatically adjusted to reflect increases in the costof-living as measured by the BLS CPI-W. Prior to 1972, Social Security benefits were enacted on an ad hoc basis by Congress. The current COLA calculation is set in December each year based on the percentage change in the average CPI-W in the third quarter over the previous year's third quarter average. (See the "Cost-Of-Living-Adjustment Fact Sheet" distributed by the Social Security Administration at https: //www.ssa.gov/pubs/EN-05-10526.pdf.)
} 
To illustrate the effect that differences in the housing inflation measures can have on Social Security benefits, we consider the differential impact of switching the actual CPI with our modified CPI in calculating the annual COLAs. Figure 12 shows the actual annual COLAs reported by the Social Security Administration 19 Since the CPI-W reported declines from the previous years in 2008 and 2009 as well as in 2014, the actual COLAs report no adjustment for years 2009, 2010, and 2015. Figure 12 also reports the estimated COLA based on the modified CPI as well as the yearly differential (actual less modified). Since our modified CPI reports higher increases than the CPI-W, the modified COLA would have resulted in no adjustment in only 2010. The differential is illustrated by the bars in Figure 12 .

Over the period from 2003 to 2016, the COLAs based on the modified CPI would have been 0.3 percent per year higher than the actual COLAs. However, following the financial crisis, COLA adjustments using the modified CPI would have been 0.8 percent per year higher. Table 12 reports the differences in accumulated benefits that would have accrued to beneficiaries under the actual and modified COLA calculations. For an individual in 2016 who had been a beneficiary for 5-years (starting in 2011), the modified COLA would have resulted in benefits that are 6.3 percent higher than the actual COLA while the benefits to an individual who had been a beneficiary for 10-years (starting in 2006) are 3.6 percent higher under the modified COLA calculation. Finally, benefits would have been 4.2 percent higher for a individual who had been a beneficiary starting in 2002 under the modified COLA calculation versus the actual COLAs. To put these in differences in perspective, for a 70year old individual that retires in 2016 the modified COLA would result in a monthly benefit that is $\$ 178$ greater than the actual benefit paid to that individual. In terms of hypothetical costs to the Social Security system, Table 13 shows that using the modified COLA to adjust benefits from 2003 to 2015 would have increased total benefit payments by approximately

\footnotetext{
19 The annual cost-of-living adjustments are reported at https://www.ssa.gov/OACT/COLA/colaseries . html. Technically, our modified CPI is based on CPI-U, but the difference between CPI-U and CPI-W is very small.
} 
$\$ 35.3$ billion (in constant 2016 dollars).

Furthermore, Novy-Marx and Rauh (2011) and Novy-Marx and Rauh (2014) note that relatively small changes in COLA calculations, such as the ones reported here, can have large effects on pension liabilities. For example, in a study of state and local government pension plans, Novy-Marx and Rauh (2011) note that a 1 percent reduction in COLAs could reduce total public pension liabilities between 9 percent to 11 percent or between $\$ 280$ billion and $\$ 470$ billion in accumulated benefit obligations (ABO) for the 116 state-sponsored pension funds included in their study. Thus, assuming a linear relationship, our 10-year estimate of 3.6 percent for the difference in COLAs implies that the actual COLAs reduced state and local government $\mathrm{ABO}$ by potentially $\$ 1.6$ trillion. ${ }^{20}$

\subsection{Real Personal Consumption Expenditures and Gross Domes- tic Products}

The modification to the PCE price index has a direct impact on the calculation of real PCE. The BEA calculates real PCE by deflating the nominal PCE by the PCE price index. Thus, an upward change to the price index has a negative effect on the real value. Furthermore, the modification to real PCE also affects real GDP because GDP is measured by adding final expenditures (i.e., using the final expenditure approach) in the U.S ${ }^{21}$ This effect is large because PCE accounts for more than 68 percent of the U.S. GDP in 2015.

To illustrate the impact of our price modification, we deflate the nominal PCE by our modified PCE price index and obtain the modified real PCE and GDP 22 Specifically, we

\footnotetext{
$20 \$ 470$ billion times 3.6.

${ }^{21}$ See Bureau of Economic Analysis (2015).

${ }^{22}$ According to Bureau of Economic Analysis (2015), "rent equals the number of occupied units times the rent per unit" with both the number of housing units and the rent per unit beign estimated from the decennial Census of Housing $(\mathrm{COH})$ and the biennial American Housing Survey (AHS). The COH ad AHS surveys use larger samples than the CPI rent survey. Thus, the numerator reflects housing expenditures based on large samples whereas the denominator is a price index based on a much smaller sample of existing tenants. As a result, our application assumes that any measurement errors in the numerator and denominator are independent and we simply demonstrate the bias that may result from mismeasurement in the denominator.
} 
first compute quarterly percentage change in real PCE by:

$$
g_{r p c e, t}=g_{n p c e, t}-i_{m o d p c e, t},
$$

where $g_{r p c e, t}$ and $g_{n p c e, t}$ denote the quarterly percentage change in real and nominal PCE, respectively, and $i_{\text {modpce,t }}$ denotes the quarterly percentage change in our modified PCE price index. By using quarterly changes, we calculate the real value in 2009 dollars and the percentage change from year ago. We then compute the modified real GDP by:

$$
r_{g d p, t}=r_{p c e, t}+r_{e l s e, t}
$$

where $r_{g d p, t}, r_{p c e, t}$, and $r_{e l s e, t}$ denote real values in 2009 dollars for GDP, PCE, and other expenditures, respectively.

Figure 13 compares the original and modified real PCE. Growth rates from year ago are almost identical until the Great Recession, but the decrease in real consumption during the recession is much more moderate on the basis of the modified value. The largest quarterly decrease was 2.81 percent per annum in 2008:IV for the modified value whereas it was 4.81 percent per annum for the original value. In contrast, the modified real consumption growth is smaller in the current recovery period. The average growth rate between 2009:III and 2016:I is 1.97 percent per annum for the modified value whereas it is 2.22 percent per annum for the original value.

Figure 14 shows a qualitatively similar effect of the price modification on real GDP. The modified real GDP decreased by 7.16 percent per annum whereas the original real GDP decreased by 8.45 percent per annum in 2008:IV. Thus, a decrease in real GDP was more moderate during the Great Recession. In contrast, the average growth rate between 2009:III and 2016:I is 1.90 percent per annum for the modified value whereas it is 2.06 percent per annum for the original value. As a result, our analysis indicating inflation over this period of 2.4 percent per year combined with average economic growth of 1.9 percent suggests that 
the U.S. economy may be experiencing a period of 'stagflation'. Thus, the lower economic growth and higher inflation may explain the consistent negative consumer sentiment and political uncertainty seen during the economic expansion following the Great Recession.

\section{Conclusion}

Housing rent is the most important component of price indexes (16 percent of PCE and 33 percent of CPI). However, the CPI rent index has several important shortcomings. These include the omission of rent changes between leases, smoothing, and lags. We develop a new investors' based net rent income index that has several advantages. The NRI is based on market prices, it reflects both new and existing leases, it is updated monthly, and is consistent with the RRI of Ambrose et al. (2015b).

Using the modified price indexes, we find that the NRI-core price indexes significantly decreased (i.e., deflation) during the Great Recession. In addition, due to a very rapid and constant increase in housing rent since 2010, the modified inflation rates were significantly higher than the traditional rates. In fact, the NRI-core CPI indicates that annual inflation rates were constantly higher than 5 percent. The NRI-core PCE indicates that annual inflation rates were approximately 3 percent whereas the traditional core PCE indicates constant

deflation. Finally, we offer two applications that demonstrate the economic significance of our estimates by examining the effect on cost-of-living adjustments and measurement of GDP. 


\section{References}

Aizcorbe, A. M. and Jackman, P. C. (1993). The commodity substitution effect in cpi data, 1982-91: Anatomy of price change. Monthly Labor Review, 4(2):25-33.

Ambrose, B. W., Coulson, N. E., and Yoshida, J. (2015a). Discretion or delay? the u.s. monetary policy in the 2000s. Working Paper.

Ambrose, B. W., Coulson, N. E., and Yoshida, J. (2015b). The repeat rent index. Review of Economics and Statistics, 97(5):939-950.

Ambrose, B. W. and Diop, M. (Forthcoming, 2014). Spillover effects of subprime mortgage originations: The effects of single-family mortgage credit expansion on the multifamily rental market. Journal of Urban Economics.

Aoki, K. (2006). Optimal commitment policy under noisy information. Journal of Economic Dynamics and Control, 30(1):81-109.

Bajari, P., Benkard, C. L., and Krainer, J. (2005). House prices and consumer welfare. Journal of Urban Economics, 58(3):474-487.

Bernanke, B. S. (2012). The Great Moderation. In Koenig, E. F., Leeson, R., and Kahn, G. A., editors, The Taylor Rule and the Transformation of Monetary Policy, Book Chapters, chapter 6. Hoover Institution, Stanford University.

Brunnermeier, M. K. and Julliard, C. (2008). Money illusion and housing frenzies. Review of Financial Studies, 21(1):135-180.

Burdick, C. and Fisher, L. (2007). Social Security Cost-of-Living Adjustments and the Consumer Price Index. Social Security Bulletin, 67(3):73-88.

Bureau of Economic Analysis (2015). Measuring the Economy: A Primer on GDP and the National Income and Product Accounts. U.S. Department of Commerce, http://www. bea.gov/national/pdf/nipa_primer.pdf.

Campbell, J. Y. and Shiller, R. J. (1988). Stock prices, earnings, and expected dividends. Journal of Finance, 43(3):661-76.

Campbell, S. D., Davis, M. A., Gallin, J., and Martin, R. F. (2009). What moves housing markets: A variance decomposition of the rent-price ratio. Journal of Urban Economics, 66(2):90-102.

Cecchetti, S. (2007). Housing in inflation measurement. VOX CEPR's Policy Portal June 13, The Centre for Economic Policy Research.

Clapp, J. M. and Giaccotto, C. (1998). Price indices based on the hedonic repeat-sales method: Application to the housing market. The Journal of Real Estate Finance and Economics, 16(1):5-26.

Clapp, J. M., Giaccotto, C., and Tirtiroglu, D. (1991). Housing price indices based on all transactions compared to repeat subsamples. Real Estate Economics, 19(3):270-285. 
Clarida, R., Gali, J., and Gertler, M. (2000). Monetary policy rules and macroeconomic stability: Evidence and some theory. The Quarterly Journal of Economics, 115(1):pp. $147-180$.

Clarida, R., Gali, J., and Gertler, M. (2002). A simple framework for international monetary policy analysis. Journal of Monetary Economics, 49(5):879-904. Carnegie-Rochester Conference on Public Policy, Carnegie Mellon University, Pittsburgh, Pennsylvania, NOV 16-17, 2001.

Clark, T. E. (2009). Is the Great Moderation over? an empirical analysis. Economic Review, (Q IV):5-42.

Crone, T. M., Nakamura, L. I., and Voith, R. (2010). Rents have been rising, not falling, in the postwar period. The Review of Economics and Statistics, 92(3):628-642.

Davidoff, T. and Yoshida, J. (2013). Estimating consumption substitution between housing and non-housing goods using macro data. Working paper.

Diewert, W. E. (1976). Exact and superlative index numbers. Journal of Econometrics, $4(2): 115-145$.

Diewert, W. E. (2009). Durables and Owner-Occupied Housing in a Consumer Price Index. In Diewert, W. E., Greenlees, J. S., and Hulten, C. R., editors, Price Index Concepts and Measurement, NBER Chapters, pages 445-500. University of Chicago Press.

Eichholtz, P., Straetmans, S., and Theebe, M. (2012). The Amsterdam rent index: The housing market and the economy, 15501850. Journal of Housing Economics, 21(4):269282.

Ermisch, J. F., Findlay, J., and Gibb, K. (1996). The price elasticity of housing demand in britain: Issues of sample selection. Journal of Housing Economics, 5(1):64-86.

Gallin, J. and Verbrugge, R. (2007). Improving the cpi's age-bias adjustment: Leverage, disaggregation and model averaging. US Department of Labor, US Bureau of Labor Statistics, Office of Prices and Living Conditions.

Gatzlaff, D. H. and Haurin, D. R. (1997). Sample selection bias and repeat-sales index estimates. The Journal of Real Estate Finance and Economics, 14(1-2):33-50.

Genesove, D. (2003). The nominal rigidity of apartment rents. Review of Economics and Statistics, 85(4):844-853.

Goda, G. S., Shoven, J. B., and Slavov, S. N. (2011). How Well Are Social Security Recipients Protected From Inflation? National Tax Journal, 64(2, 1):429-449.

Gordon, R. J., Davis, R. G., and Rich, G. (1993). Price Stabilization in the 1990s: Domestic and International Policy Requirements, chapter Measuring the Aggregate Price Level: Implications for Economic Performance and Policy, pages 233-276. Palgrave Macmillan UK, London. 
Gordon, R. J. and vanGoethem, T. (2007). Downward Bias in the Most Important CPI Component: The Case of Rental Shelter, 1914-2003. In Berndt, E. and Hulten, C., editors, Hard-to-Measure Goods and Services: Essays in Honor of Zvi Griliches, National Bureau of Economic Research Studies in Income and Wealth, pages 153-195. University of Chicago Press.

Green, R. K. and Malpezzi, S. (2003). A Primer on U.S. Housing Markets and Housing Policy. Urban Institute Press, Washington, D.C., USA.

Griliches, Z. and Cockburn, I. (1994). Generics and new goods in pharmaceutical price indexes. The American Economic Review, 84(5):1213-1232.

Halket, J. and Custoza, M. P. M. d. (2015). Homeownership and the scarcity of rental. Journal of Monetary Economics, 76:107-123.

Handbury, J., Watanabe, T., and Weinstein, D. E. (2015). How much do official price indexes tell us about inflation? Working Paper 19504, National Bureau of Economic Research.

Harmon, O. R. (1988). The income elasticity of demand for single-family owner-occupied housing: An empirical reconciliation. Journal of Urban Economics, 24(2):173-185.

Hausman, J. (2003). Sources of bias and solutions to bias in the consumer price index. The Journal of Economic Perspectives, 17(1):23-44.

Himmelberg, C., Mayer, C., and Sinai, T. (2005). Assessing high house prices: Bubbles, fundamentals and misperceptions. Journal of Economic Perspectives, 19(4):67-92.

Lane, W. F., Randolph, W. C., and Berenson, S. A. (1988). Adjusting the cpi shelter index to compensate for effect of depreciation. Monthly Labor Review, pages 34-37.

Lebow, D. E. and Rudd, J. B. (2003). Measurement error in the consumer price index: Where do we stand? Journal of Economic Literature, 41(1):159-201.

Mankiw, N. and Weil, D. N. (1989). The baby boom, the baby bust, and the housing market. Regional Science and Urban Economics, 19(2):235 - 258.

Manser, M. E. and McDonald, R. J. (1988). An analysis of substitution bias in measuring inflation, 1959-85. Econometrica, 56(4):909-930.

Mayo, S. K. (1981). Theory and estimation in the economics of housing demand. Journal of Urban Economics, 10(1):95-116.

McCarthy, J. and Peach, R. W. (2004). Are home prices the next "bubble"? Economic Policy Review, pages 1-17.

McCarthy, J. and Peach, R. W. (2010). The measurement of rent inflation. Staff Reports 425, Federal Reserve Bank of New York.

McMillen, D. P. and Thorsnes, P. (2006). Housing renovations and the quantile repeat-sales price index. Real Estate Economics, 34(4):567-584.

Meese, R. A. and Wallace, N. E. (1997). The construction of residential housing price indices: A comparison of repeat-sales, hedonic-regression and hybrid approaches. The Journal of Real Estate Finance and Economics, 14(1-2):51-73. 
Moulton, B. R. and Moses, K. E. (1997). Addressing the Quality Change Issue in the Consumer Price Index. Brookings Papers on Economic Activity, 28(1):305-366.

Nelson, C. and Plosser, C. (1982). Trends and random-walks in macroeconomic time-series - some evidence and implications. Journal of Monetary Economics, 10(2):139-162.

Novy-Marx, R. and Rauh, J. D. (2011). Policy options for state pension systems and their impact on plan liabilities. Journal of Pension Economics and Finance, 10:173-194.

Novy-Marx, R. and Rauh, J. D. (2014). Linking benefits to investment performance in US public pension systems. Journal of Public Economics, 116():47-61.

Ozimek, A. (2014). Sticky rents and the cpi for owner-occupied housing. Working Paper.

Poterba, J. M. (1984). Tax subsidies to owner-occupied housing: An asset-market approach. The Quarterly Journal of Economics, 99(4):pp. 729-752.

Reinsdorf, M. (1993). The Effect of Outlet Price Differentials on the U.S. Consumer Price Index. In Murry Foss, M. M. and Young, A., editors, Price Measurements and Their Uses. University of Chicago Press.

Reinsdorf, M. and Triplett, J. E. (2009). A Review of Reviews: Ninety Years of Professional Thinking About the Consumer Price Index. In Diewert, W. E., Greenlees, J. S., and Hulten, C. R., editors, Price Index Concepts and Measurement, NBER Chapters, pages 17-83. University of Chicago Press.

Shapiro, M. D. and Wilcox, D. W. (1996). Mismeasurement in the consumer price index: An evaluation. Working Paper 5590, National Bureau of Economic Research.

Shiller, R. J. (1991). Arithmetic repeat sales price estimators. Journal of Housing Economics, 1(1):110 - 126 .

Shimizu, C., Nishimura, K. G., and Watanabe, T. (2010). Residential rents and price rigidity: Micro structure and macro consequences. Journal of the Japanese and International Economies, 24(2):282-299.

Sinai, T. and Souleles, N. S. (2005). Owner-occupied housing as a hedge against rent risk. The Quarterly Journal of Economics, 120(2):763-789.

Stock, J. H. and Watson, M. W. (2002). Has the Business Cycle Changed and Why? NBER Working Papers 9127, National Bureau of Economic Research, Inc.

Summers, L. H. (1981). Inflation, the stock market, and owner-occupied housing. The American Economic Review, 71(2):pp. 429-434.

Svensson, L. E. and Woodford, M. (2004). Implementing Optimal Policy through InflationForecast Targeting. In The Inflation-Targeting Debate, NBER Chapters, pages 19-92. University of Chicago Press.

Taylor, J. B. (1993a). Discretion versus policy rules in practice. Carnegie-Rochester Conference Series on Public Policy, 39:195-214.

Taylor, J. B. (1993b). Macroeconomic Policy in a World Economy: From Econometric Design to Practical Operation. W.W. Norton. 
Topel, R. and Rosen, S. (1988). Housing investment in the united states. Journal of Political Economy, 96(4):pp. 718-740.

U.S. Bureau of Economic Analysis (2012). Does the Bureau of Economic Analysis (BEA) publish relative-importance weights used in the derivation of chain-type quantity and price indexes for personal consumption expenditures (PCE)? FAQ 1006, BEA.

Verbrugge, R. (2008). The puzzling divergence of rents and user costs, 1980-2004. Review of Income and Wealth, 54(4):671-699.

Verbrugge, R. and Poole, R. (2010). Explaining the rentoer inflation divergence, 1999-2007. Real Estate Economics, 38(4):633-657.

Wheaton, W. C. and Nechayev, G. (2009). What will it take to restore the housing market? Working Paper 09-06, MIT Department of Economics. 


\begin{tabular}{|c|c|c|c|c|c|c|}
\hline & \multicolumn{3}{|c|}{ CPI } & \multicolumn{3}{|c|}{$\mathrm{PCE}$} \\
\hline & $\begin{array}{c}\text { Shelter } \\
\text { (1) }\end{array}$ & $\begin{array}{l}\text { Core } \\
(2)\end{array}$ & $\begin{array}{c}\text { Shelter } \\
\text { in Core CPI } \\
(3)=(1) /(2)\end{array}$ & $\begin{array}{l}\text { Housing } \\
\text { (4) }\end{array}$ & $\begin{array}{l}\text { Core } \\
(5)\end{array}$ & $\begin{array}{c}\text { Housing } \\
\text { in Core PCE } \\
(6)=(4) /(5)\end{array}$ \\
\hline 1997 & 0.294 & 0.777 & 0.379 & 0.151 & 0.865 & 0.174 \\
\hline 1998 & 0.299 & 0.783 & 0.382 & 0.151 & 0.874 & 0.173 \\
\hline 1999 & 0.299 & 0.777 & 0.384 & 0.150 & 0.875 & 0.172 \\
\hline 2000 & 0.299 & 0.771 & 0.388 & 0.149 & 0.873 & 0.170 \\
\hline 2001 & 0.312 & 0.791 & 0.394 & 0.153 & 0.874 & 0.175 \\
\hline 2002 & 0.314 & 0.787 & 0.398 & 0.153 & 0.880 & 0.174 \\
\hline 2003 & 0.325 & 0.785 & 0.414 & 0.152 & 0.877 & 0.173 \\
\hline 2004 & 0.323 & 0.777 & 0.416 & 0.150 & 0.875 & 0.172 \\
\hline 2005 & 0.319 & 0.774 & 0.412 & 0.152 & 0.870 & 0.174 \\
\hline 2006 & 0.324 & 0.774 & 0.419 & 0.152 & 0.869 & 0.175 \\
\hline 2007 & 0.323 & 0.765 & 0.422 & 0.152 & 0.867 & 0.175 \\
\hline 2008 & 0.329 & 0.777 & 0.423 & 0.154 & 0.862 & 0.179 \\
\hline 2009 & 0.319 & 0.777 & 0.411 & 0.162 & 0.871 & 0.186 \\
\hline 2010 & 0.316 & 0.772 & 0.410 & 0.158 & 0.868 & 0.182 \\
\hline 2011 & 0.312 & 0.760 & 0.410 & 0.155 & 0.864 & 0.180 \\
\hline 2012 & 0.313 & 0.761 & 0.412 & 0.154 & 0.867 & 0.178 \\
\hline 2013 & 0.317 & 0.771 & 0.411 & 0.154 & 0.868 & 0.177 \\
\hline 2014 & 0.323 & 0.777 & 0.416 & 0.154 & 0.872 & 0.176 \\
\hline 2015 & 0.328 & 0.792 & 0.414 & 0.155 & 0.883 & 0.175 \\
\hline 2016 & 0.328 & 0.792 & 0.414 & 0.156 & 0.890 & 0.175 \\
\hline
\end{tabular}

This table shows the relative importance of Shelter in the all-item and core CPI (columns (1) and (3)) and Housing in the headilne and core PCE price index (columns (4) and (6)). The relative importance for CPI is available at: http://www.bls.gov/ cpi/cpiriar.htm. For the PCE, we follow U.S. Bureau of Economic Analysis (2012) and use current-dollar PCE expenditures as the relative importance weights. The weight in 2016 is extrapolated from 2015 for CPI and based on the first-quarter data for PCE.

Table 1: Relative Importance of Housing in Price Indexes 


\begin{tabular}{|c|c|c|c|c|}
\hline & \multicolumn{2}{|c|}{ CPI Shelter } & \multicolumn{2}{|c|}{ PCE Housing } \\
\hline & $\begin{array}{c}\text { Rent of } \\
\text { Primary Residence }\end{array}$ & $\begin{array}{c}\text { Owners' } \\
\text { Equivalent Rent }\end{array}$ & $\begin{array}{c}\text { Rental of } \\
\text { Tenant-Occupied } \\
\text { Housing }\end{array}$ & $\begin{array}{c}\text { Imputed Rental of } \\
\text { Owner-Occupied } \\
\text { Housing }\end{array}$ \\
\hline 1997 & 0.234 & 0.687 & 0.237 & 0.750 \\
\hline 1998 & 0.234 & 0.686 & 0.234 & 0.754 \\
\hline 1999 & 0.236 & 0.685 & 0.230 & 0.758 \\
\hline 2000 & 0.237 & 0.685 & 0.226 & 0.761 \\
\hline 2001 & 0.206 & 0.707 & 0.223 & 0.764 \\
\hline 2002 & 0.206 & 0.709 & 0.220 & 0.767 \\
\hline 2003 & 0.189 & 0.720 & 0.211 & 0.776 \\
\hline 2004 & 0.190 & 0.717 & 0.206 & 0.780 \\
\hline 2005 & 0.183 & 0.735 & 0.201 & 0.784 \\
\hline 2006 & 0.183 & 0.735 & 0.202 & 0.783 \\
\hline 2007 & 0.179 & 0.742 & 0.213 & 0.772 \\
\hline 2008 & 0.181 & 0.743 & 0.218 & 0.768 \\
\hline 2009 & 0.187 & 0.789 & 0.226 & 0.760 \\
\hline 2010 & 0.187 & 0.788 & 0.231 & 0.755 \\
\hline 2011 & 0.208 & 0.768 & 0.242 & 0.743 \\
\hline 2012 & 0.209 & 0.767 & 0.245 & 0.742 \\
\hline 2013 & 0.220 & 0.755 & 0.242 & 0.744 \\
\hline 2014 & 0.221 & 0.753 & 0.246 & 0.740 \\
\hline 2015 & 0.236 & 0.739 & 0.248 & 0.739 \\
\hline 2016 & 0.236 & 0.739 & 0.248 & 0.739 \\
\hline
\end{tabular}

This table shows the proportions of tenant- and owner-occupied housing in CPI shelter and PCE Housing. The relative importance for CPI is available at: http://www.bls.gov/cpi/cpiriar.htm. For the PCE, we follow U.S. Bureau of Economic Analysis (2012) and use current-dollar PCE expenditures as the relative importance weights. The weight in 2016 is extrapolated from 2015 for CPI and based on the first-quarter data for PCE.

Table 2: Components of CPI Shelter and PCE Housing 


\begin{tabular}{crc}
\hline Number of lags $(\mathrm{n})$ & \multicolumn{1}{c}{$\mathrm{F}$} & Adjusted R-squared \\
\hline 0 & 2.74 & 0.04 \\
1 & 10.54 & 0.21 \\
2 & 27.45 & 0.42 \\
3 & 71.00 & 0.65 \\
4 & 183.72 & 0.83 \\
5 & 291.30 & 0.89 \\
6 & 177.88 & 0.83 \\
7 & 65.47 & 0.64 \\
8 & 26.71 & 0.41 \\
\hline
\end{tabular}

This table shows the F-statistic and the adjusted R-squared of a regression: $g_{P C E, t}=\alpha+\beta g_{R R I, t-n}+\varepsilon$, where $g_{P C E, t}$ is the percentage change from year ago in the PCE rent for tenantoccupied housing, $g_{R R I, t-n}$ is the n-quarter lagged percentage change from year ago in the Repeat Rent Index, and $\varepsilon$ is the error term. The number of observations is 38 quarters for all specifications.

Table 3: Lags in the PCE Rent Index

\begin{tabular}{lcccc}
\hline & (A) & (B) & (C) & (D) \\
\hline (A) Net Rent Index & 1 & & & \\
(B) Repeat Rent Index & 0.858 & 1 & & \\
(C) PCE Rent (5-quarter lead) & 0.884 & 0.950 & 1 & \\
(D) PCE Rent (Contemporaneous) & 0.512 & 0.255 & 0.340 & 1 \\
\hline
\end{tabular}

This table shows the pairwise correlation coefficient between year-over-year percentage changes in alternative rent indexes. The coefficients are calculated based on 33 quarters between 2002:I-2010:I. The Net Rent Index reflects the average net rent for both new and existing tenants, the Repeat Rent Index reflects the gross rent for new tenants (i.e., marginal rents), and the PCE Rent reflects the gross rent for the existing tenants (i.e., inframarginal rents).

Table 4: Correlation Coefficients Between Alternative Rent Indexes 
(1) (2)

\begin{tabular}{llrr} 
VARIABLES & Data Period & Mean & S.D. \\
\hline Net Rent Index & 2001:II-2016:I & -0.216 & 3.169 \\
PCE Rent & 1959:II-2016:I & 0.753 & 0.322 \\
Repeat Rent Index & 2000:I-2010:I & -0.112 & 1.394 \\
Marginal Rent Index & 2000:II-2016:I & -0.112 & 1.394 \\
Average Rent Index & 2000:I-2010:I & 0.421 & 0.597 \\
Gross Rent Index & 2001:II-2016:I & 0.421 & 0.597
\end{tabular}

This table shows the mean and variance of quarterly percentage change in alternative rent indexes over 36 quarters between 2001:II and 2010:I. The Net Rent Index reflects the average net rent for both new and existing tenants, the PCE Rent for tenantoccupied housing reflects the gross rent for the existing tenants (i.e., inframarginal rents), and the Repeat Rent Index reflects the gross rent for new tenants (i.e., marginal rents). The Marginal Rent Index is an adjusted Net Rent Index whose mean and variance are matched with those of the Repeat Rent Index. The Average Rent Index is a weighted average of the PCE Rent and the Repeat Rent Index $(0.3 \times P C E+0.7 \times R R I)$. The Gross Rent Index is an adjusted Net Rent Index whose mean and variance are matched with those of the Average Rent Index.

Table 5: Mean and Variance of Rent Indexes 


\title{
DEPENDENT VARIABLE: \\ Quarterly change in the 5-quarter lead PCE Rent
}

$\begin{array}{lc}\text { D (2009:III-2014:IV) } & -0.181^{* * *} \\ & (0.0548) \\ \text { Net Rent Index } & 0.0389 \\ & (0.0234) \\ \text { Net Rent Index } \times & 0.0127 \\ \text { D }(2009: \text { III-2014:IV) } & (0.0262) \\ \text { Constant } & 0.769^{* * *}\end{array}$

$(0.0423)$

\begin{abstract}
Observations
48

This table shows the result of regressions of the quarterly percentage change in the 5-quarter lead PCE rent on the quarterly percentage change in the Net Rent Index. The data period is between 2001:II-2014:IV but excludes an NBER recession period that corresponds to the Great Recession (between 2007:IV and 2009:II). D (2009:III-2014:IV) denotes a dummy variable that takes the value of one after the Great Recession (2009:III-2014:IV). The Newey-West heteroskedasticity and autocorrelation corrected standard errors (2-quarter lags) are in parentheses. ${ }^{* * *},{ }^{* *}$, and ${ }^{*}$ indicate significance at the $1 \%, 5 \%$, and $10 \%$ level, respectively.
\end{abstract}

Table 6: Relation between the Net Rent Index and the 5-quarter lead in PCE Rent 


\begin{tabular}{lccccc}
\hline Variable & $\mathrm{N}$ & Mean & S.D. & Min. & Max. \\
\hline Net Rent Index & 60 & $0.95 \%$ & $2.96 \%$ & $-10.15 \%$ & $5.47 \%$ \\
Vacancy-Adjusted NRI & 60 & $0.92 \%$ & $2.86 \%$ & $-9.64 \%$ & $5.01 \%$ \\
p-value & 0.62 & 0.79 & & \\
\hline
\end{tabular}

This table shows the summary statistics of the quarterly percentage change in the Net Rent Index and the Vacancy-Adjusted Net Rent Index. The VacancyAdjusted Net Rent Index is calculated as: Net Rent Index/(1 - Vacancy). The $\mathrm{p}$-value is the result of the t-test of equal means and the F-test of equal variance.

Table 7: The Effect of Vacancy Rate

\begin{tabular}{lccc}
\hline & Net Rent Index & Vacancy-Adjusted NRI & Vacancy Rate \\
\hline Net Rent Index & 1 & & \\
Vacancy-Adjusted NRI & 0.992 & 1 & 1 \\
Vacancy Rate & -0.462 & -0.445 & 1 \\
\hline
\end{tabular}

This table shows the correlation coefficients between Vacancy Rates and the quarterly percentage change in Net Rent Index and Vacancy-Adjusted Net Rent Index. Vacancy-Adjusted Net Rent Index is calculated as: Net Rent Index/(1-Vacancy). The p-value is the result of the t-test of equal means and the F-test of equal variance.

Table 8: Correlation Coefficients The Effect of Vacancy Rate 


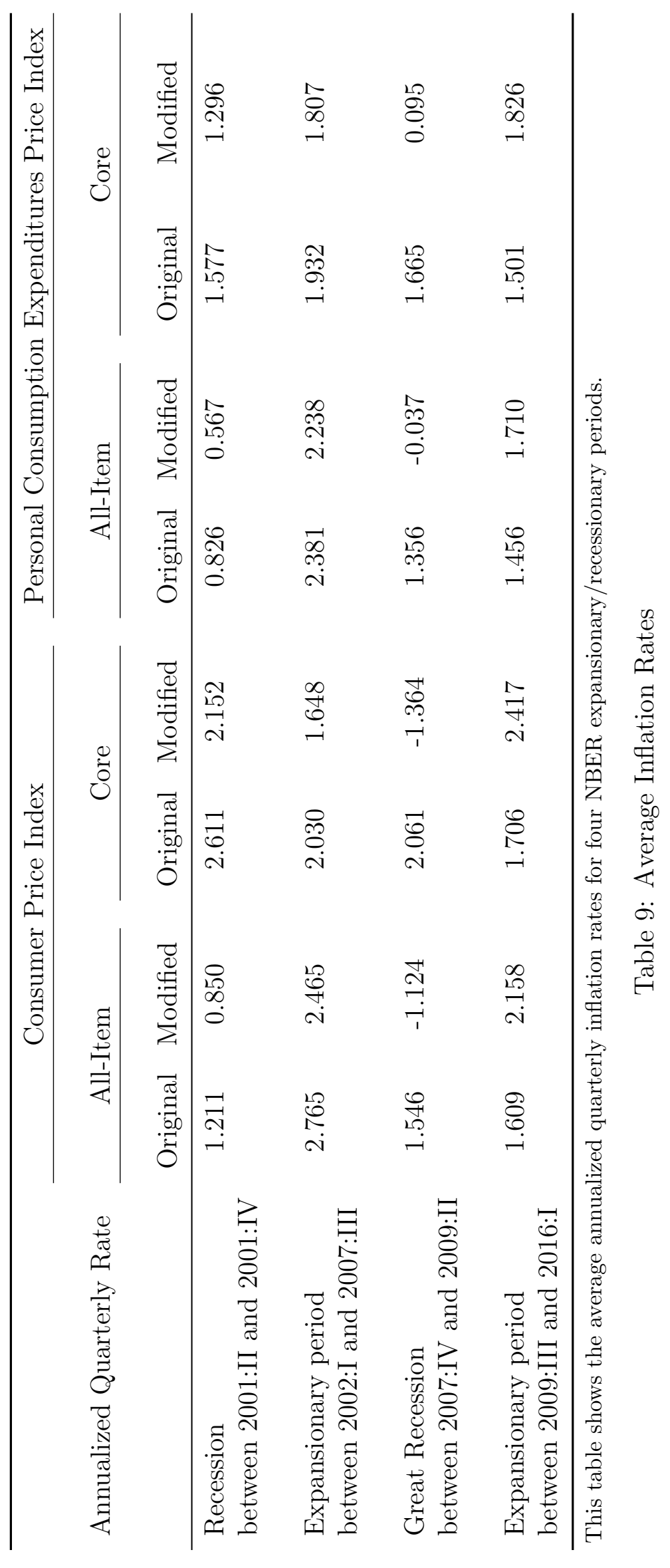




\begin{tabular}{|c|c|c|c|c|}
\hline & \multicolumn{2}{|c|}{ All-Item } & \multicolumn{2}{|c|}{ Core } \\
\hline & CPI & $\mathrm{PCE}$ & CPI & $\mathrm{PCE}$ \\
\hline $\begin{array}{l}\text { Recessionary period } \\
\text { between 2001:II and 2001:IV }\end{array}$ & -0.361 & -0.259 & -0.459 & -0.281 \\
\hline $\begin{array}{l}\text { Expansionary period } \\
\text { between 2002:I and 2007:III }\end{array}$ & -0.3 & -0.143 & -0.382 & -0.125 \\
\hline $\begin{array}{l}\text { Great Recession } \\
\text { between 2007:IV and 2009:II }\end{array}$ & -2.67 & -1.393 & -3.425 & -1.57 \\
\hline $\begin{array}{l}\text { Expansionary period } \\
\text { between 2009:III and 2016:I }\end{array}$ & 0.548 & 0.254 & 0.711 & 0.325 \\
\hline
\end{tabular}

This table shows the average difference in inflation rates between the original and modified measures for four NBER expansionary/recessionary periods. A negative number indicates that the modified inflation rate is lower than the original inflation rate.

Table 10: Difference in the Annualized Inflation Rates between the Original and Modified Measures 


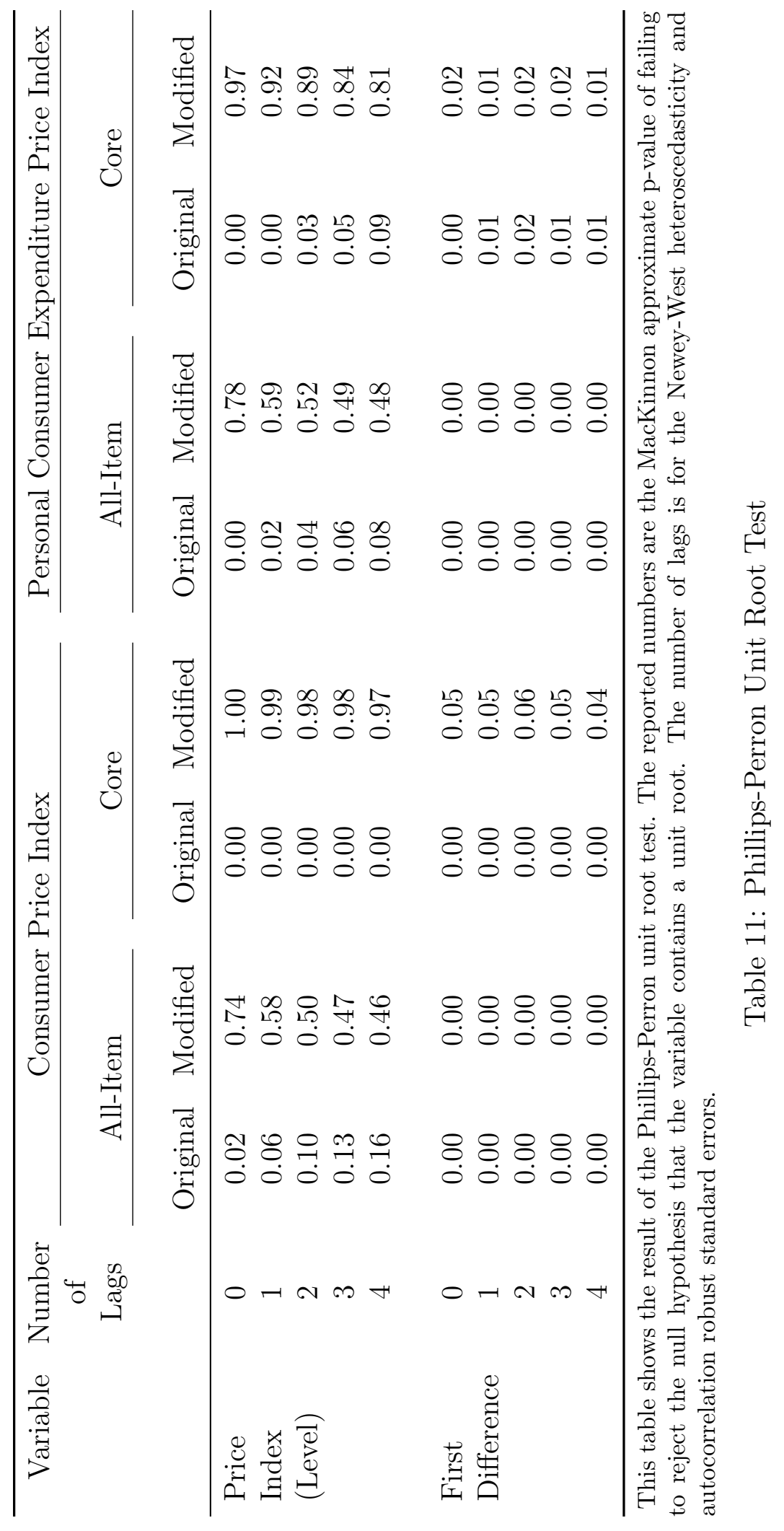




\begin{tabular}{lcc}
\hline \multirow{2}{*}{$\begin{array}{l}\text { Starting Year and number } \\
\text { of years in beneficiary status }\end{array}$} & \multicolumn{2}{c}{ Accumulated Cola } \\
Modified & Actual \\
\hline 2011 (5-years) & $36.8 \%$ & $30.5 \%$ \\
2006 (10-years) & $20.0 \%$ & $16.4 \%$ \\
2002 (14-years) & $12.9 \%$ & $8.8 \%$ \\
\hline
\end{tabular}

This table shows cumulative benefit in 2016 accruing to a beneficiary under the actual and modified COLAs. The number in parentheses indicates the total years in beneficiary status.

Table 12: Accumulative Benefit Increases from COLAs as of 2016 (in percent)

\begin{tabular}{llllllll}
\hline Year & $\begin{array}{l}\text { Beneficiaries Benefit } \\
\text { (millions) }\end{array}$ & $\begin{array}{l}\text { May- } \\
\text { ments } \\
\text { (billion) }\end{array}$ & $\begin{array}{l}\text { COLA } \\
\text { (billion) }\end{array}$ & $\begin{array}{l}\text { Actual } \\
\text { COLA } \\
\text { (billion) }\end{array}$ & $\begin{array}{l}\text { Difference } \\
(\mathrm{A})\end{array}$ & $\begin{array}{l}\text { Cumulative } \\
\text { Difference } \\
\text { (billion }\end{array}$ & $\begin{array}{l}\text { Inflation } \\
\text { Factor }\end{array}$ \\
\hline & & $(\mathrm{B})$ & $(\mathrm{A})-(\mathrm{B})$ & & \\
\hline 2003 & 46.4 & $\$ 453.8$ & $\$ 458.1$ & $\$ 465.6$ & $-\$ 7.5$ & $-\$ 7.7$ & 2.27 \\
2004 & 47 & $\$ 470.8$ & $\$ 477.9$ & $\$ 477.4$ & $\$ 0.5$ & $-\$ 7.4$ & 2.68 \\
2005 & 47.7 & $\$ 493.3$ & $\$ 504.9$ & $\$ 503.7$ & $\$ 1.3$ & $-\$ 6.3$ & 3.39 \\
2006 & 48.4 & $\$ 520.7$ & $\$ 543.1$ & $\$ 534.8$ & $\$ 8.4$ & $\$ 2.1$ & 3.23 \\
2007 & 49.1 & $\$ 546.2$ & $\$ 559.9$ & $\$ 568.6$ & $-\$ 8.7$ & $-\$ 6.8$ & 2.85 \\
2008 & 49.9 & $\$ 585.0$ & $\$ 599.1$ & $\$ 604.3$ & $-\$ 5.2$ & $-\$ 12.4$ & 3.84 \\
2009 & 50.9 & $\$ 615.4$ & $\$ 638.4$ & $\$ 629.6$ & $\$ 8.8$ & $-\$ 3.6$ & -0.36 \\
2010 & 52.5 & $\$ 675.5$ & $\$ 675.5$ & $\$ 675.5$ & $\$ 0.0$ & $-\$ 3.6$ & 1.64 \\
2011 & 54 & $\$ 701.6$ & $\$ 713.3$ & $\$ 701.6$ & $\$ 11.7$ & $\$ 8.3$ & 3.16 \\
2012 & 55.4 & $\$ 725.1$ & $\$ 755.5$ & $\$ 751.2$ & $\$ 4.3$ & $\$ 12.8$ & 2.07 \\
2013 & 56.8 & $\$ 774.8$ & $\$ 792.4$ & $\$ 788.0$ & $\$ 4.4$ & $\$ 17.5$ & 1.46 \\
2014 & 58 & $\$ 812.3$ & $\$ 834.3$ & $\$ 824.5$ & $\$ 9.8$ & $\$ 27.7$ & 1.62 \\
2015 & 59 & $\$ 848.5$ & $\$ 870.5$ & $\$ 862.9$ & $\$ 7.5$ & $\$ 35.3$ & 0.12 \\
\hline
\end{tabular}

This table shows yearly change in actual total Social Security benefit payments and total benefits based on the modified COLA calculation.

Table 13: Year Over Year Change to Average Monthly Benefits from COLA Adjustments 


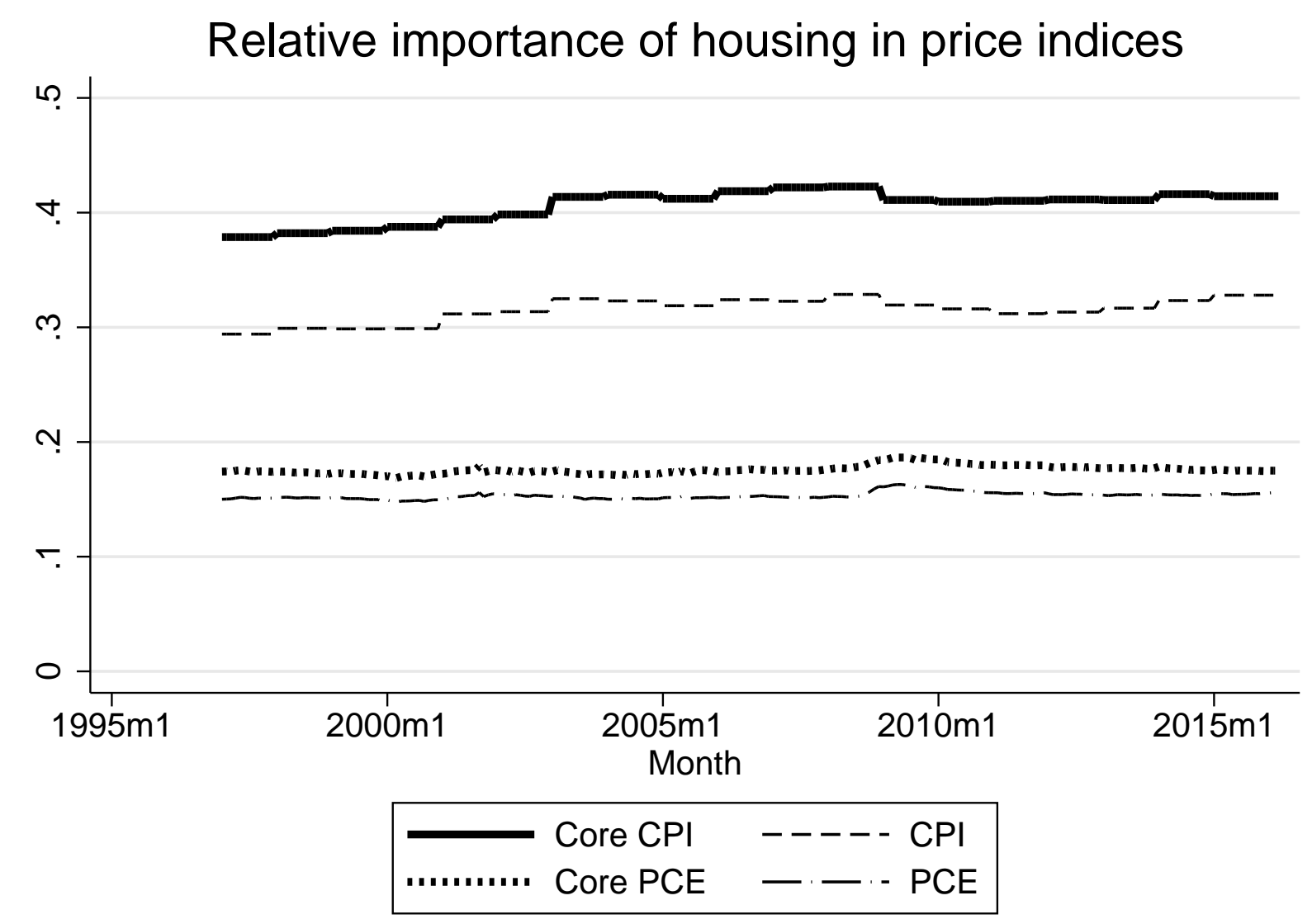

Figure 1 


\section{CPPI and Cap Rate for apartments}

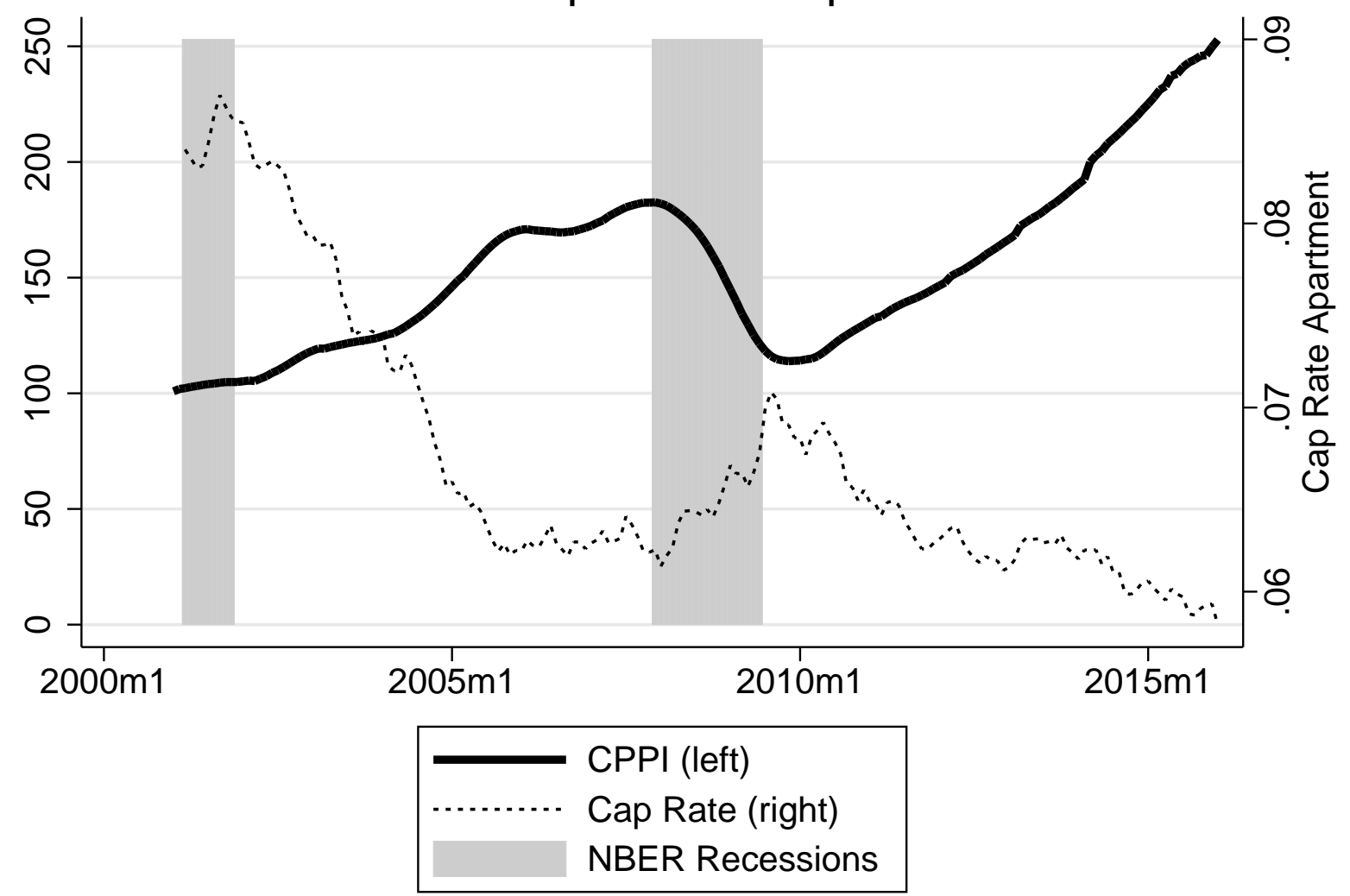

Figure 2: CPPI and Capitalization Rate for Apartments 


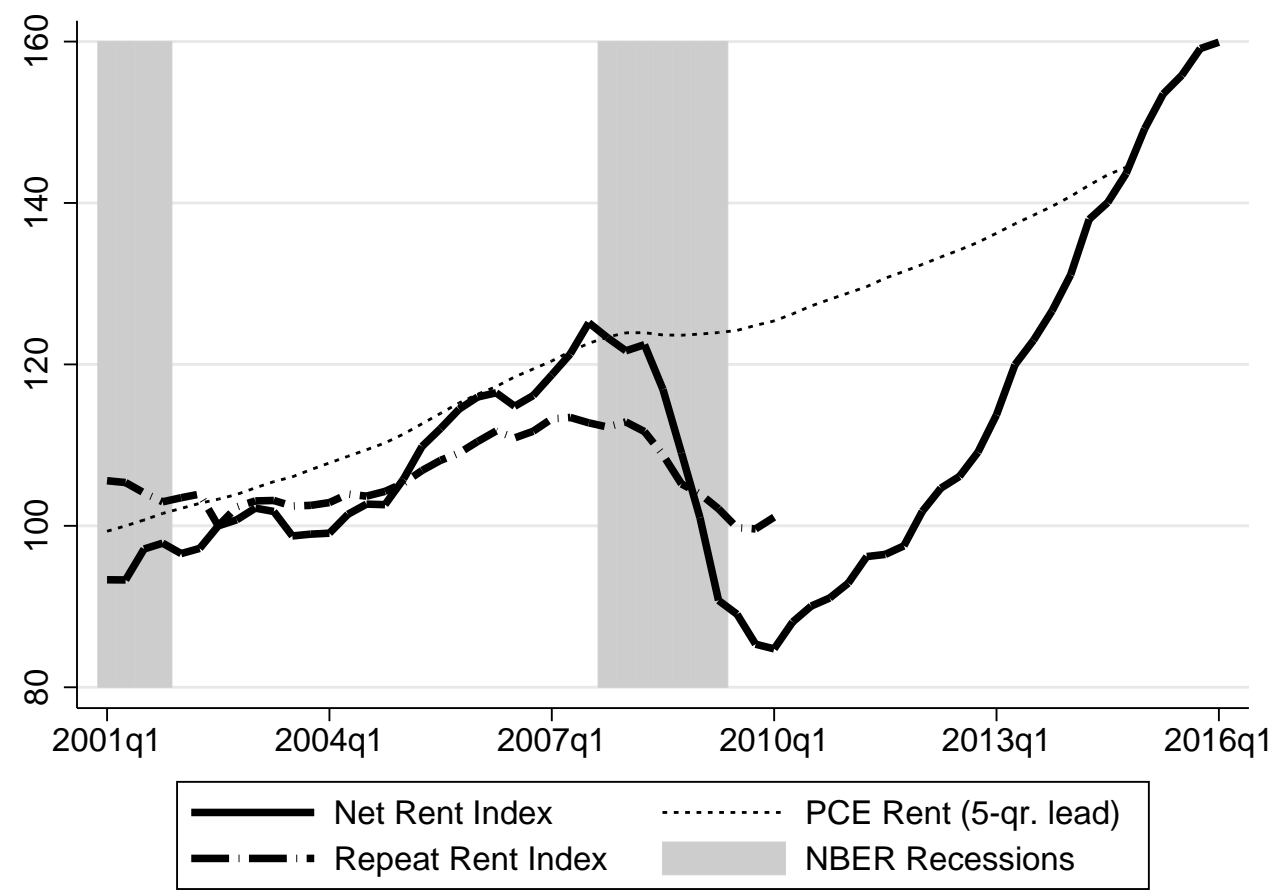

(a) Index Level

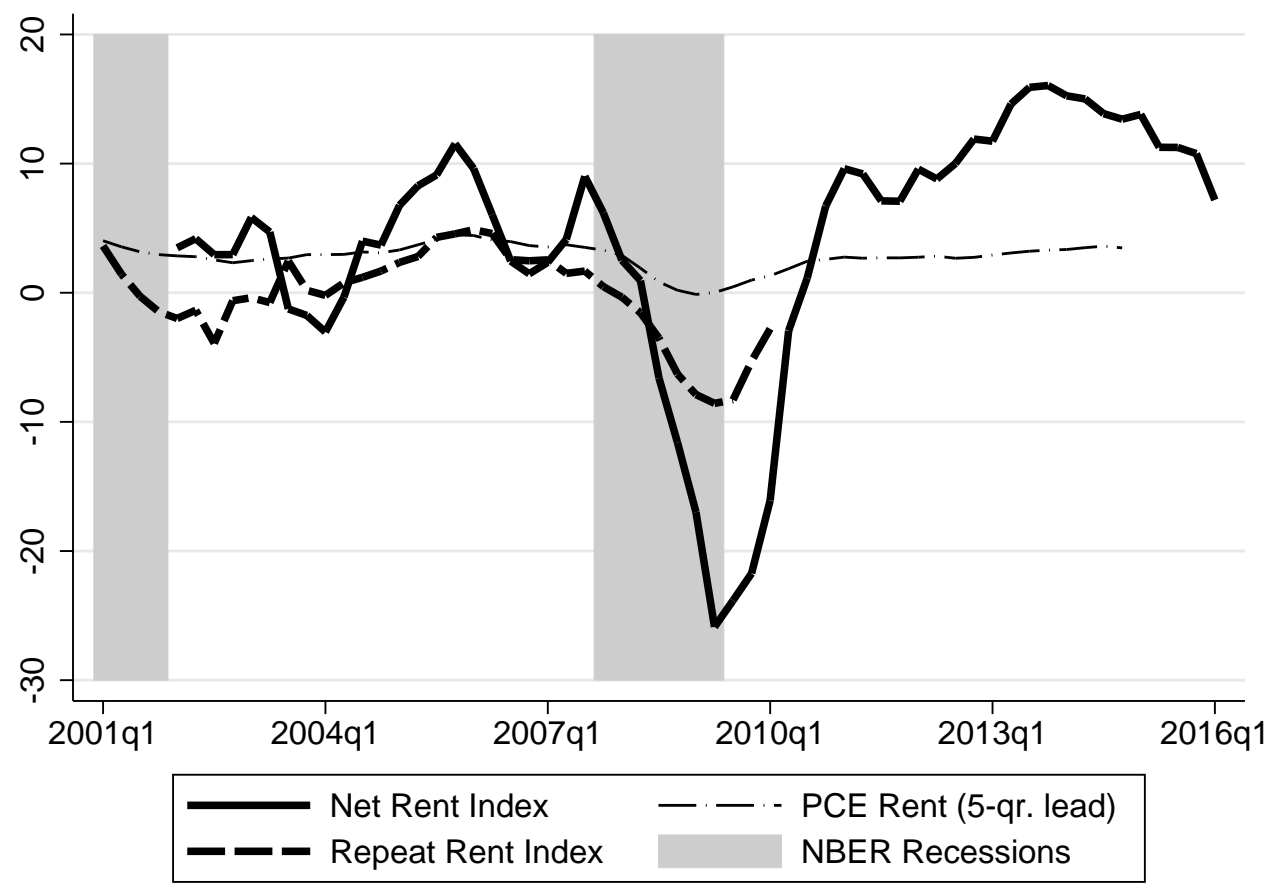

(b) Percentage Change from Year Ago

Figure 3: Comparison of Net Rent Index, PCE Rent, and Repeat Rent Index 


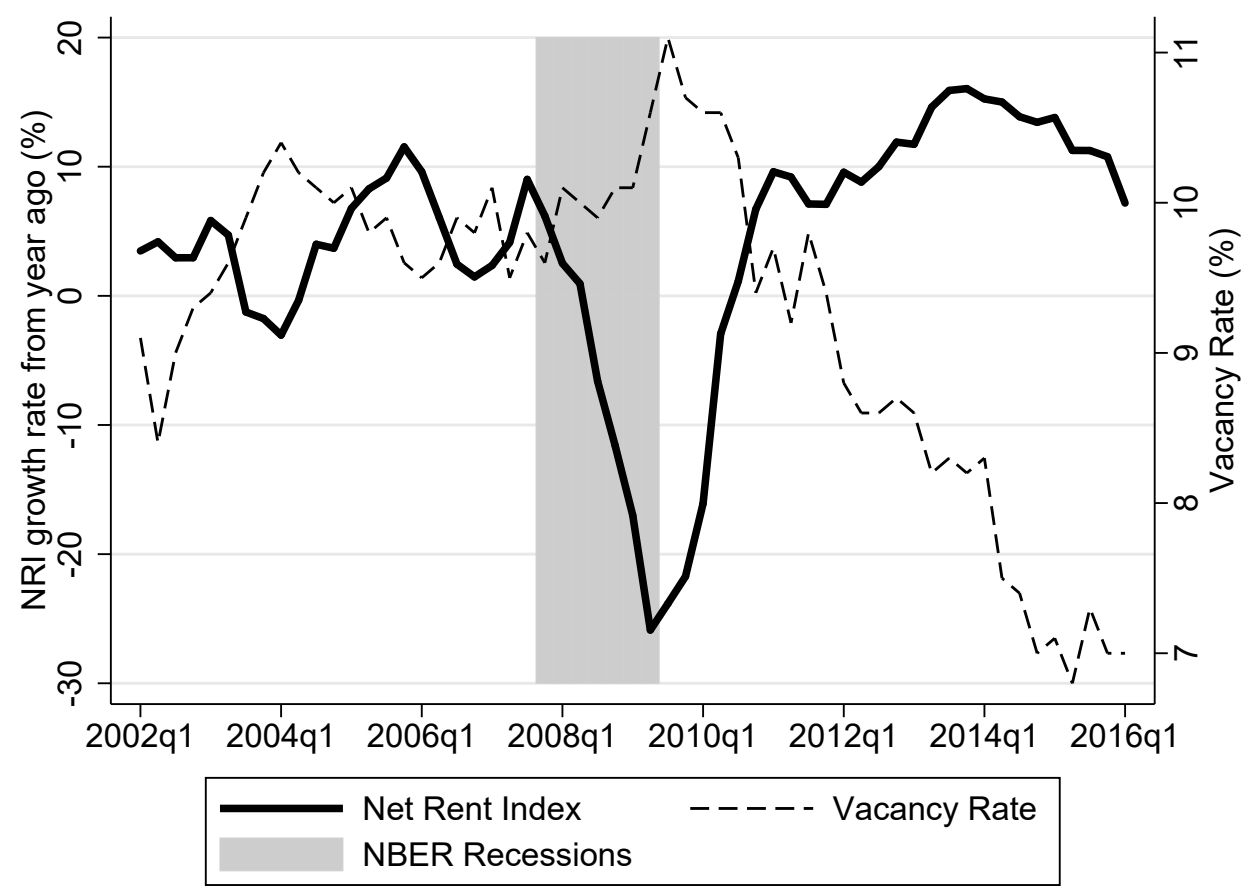

(a) Net Rent Index and Vacancy Rate

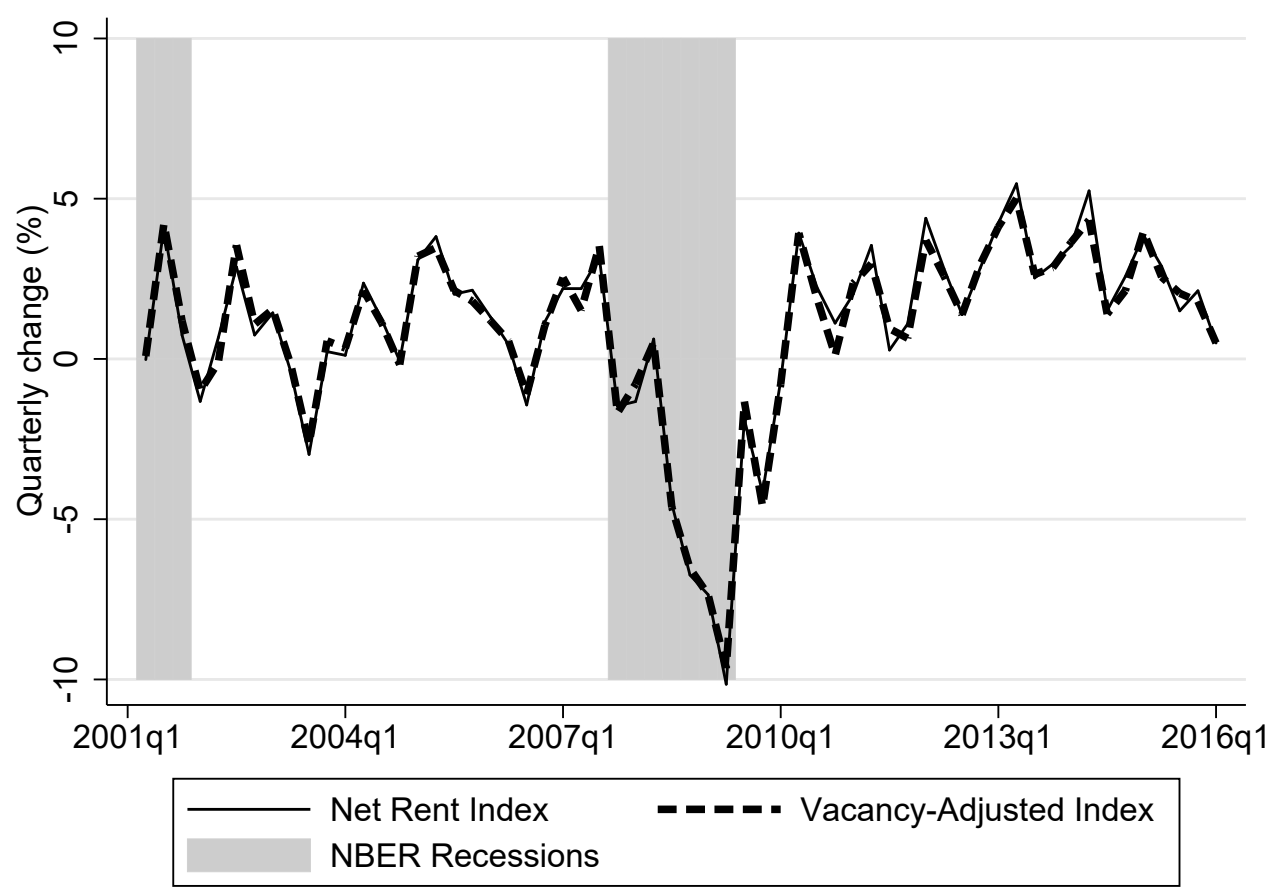

(b) Vacancy-Adjusted Net Rent Index

Figure 4: The Effect of Vacancy Rate 


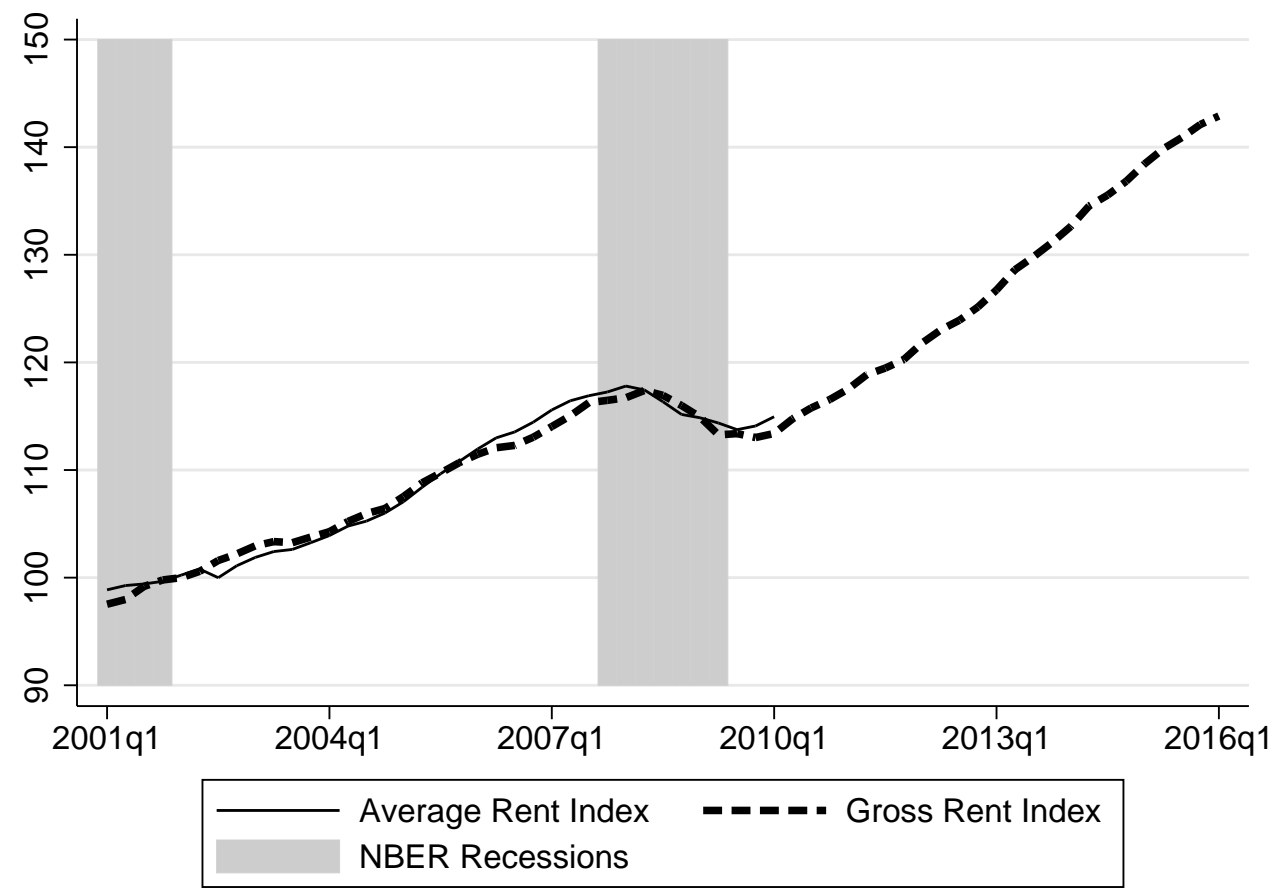

(a) Index Level

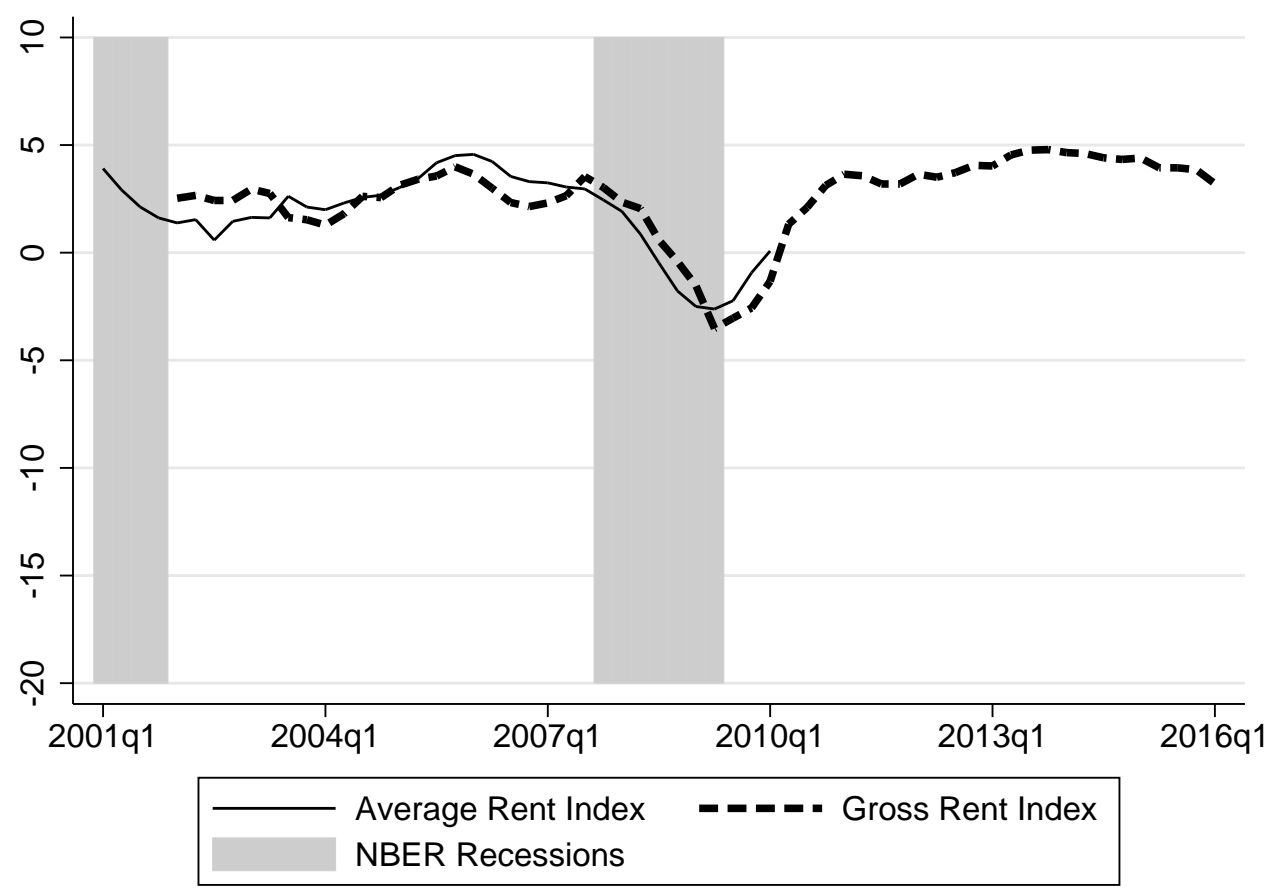

(b) Percentage change from Year Ago

Figure 5: Average Rent Index and Gross Rent Index 


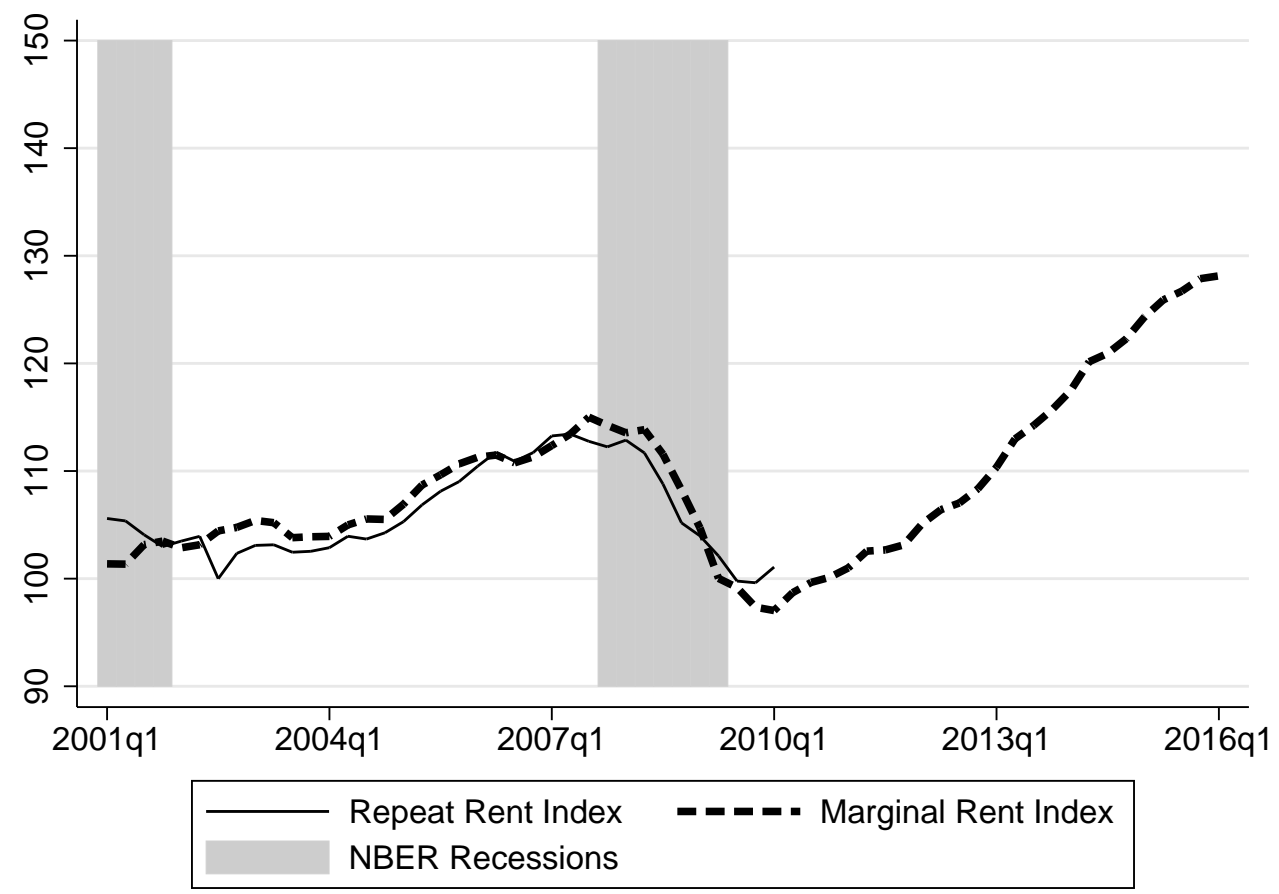

(a) Index Level

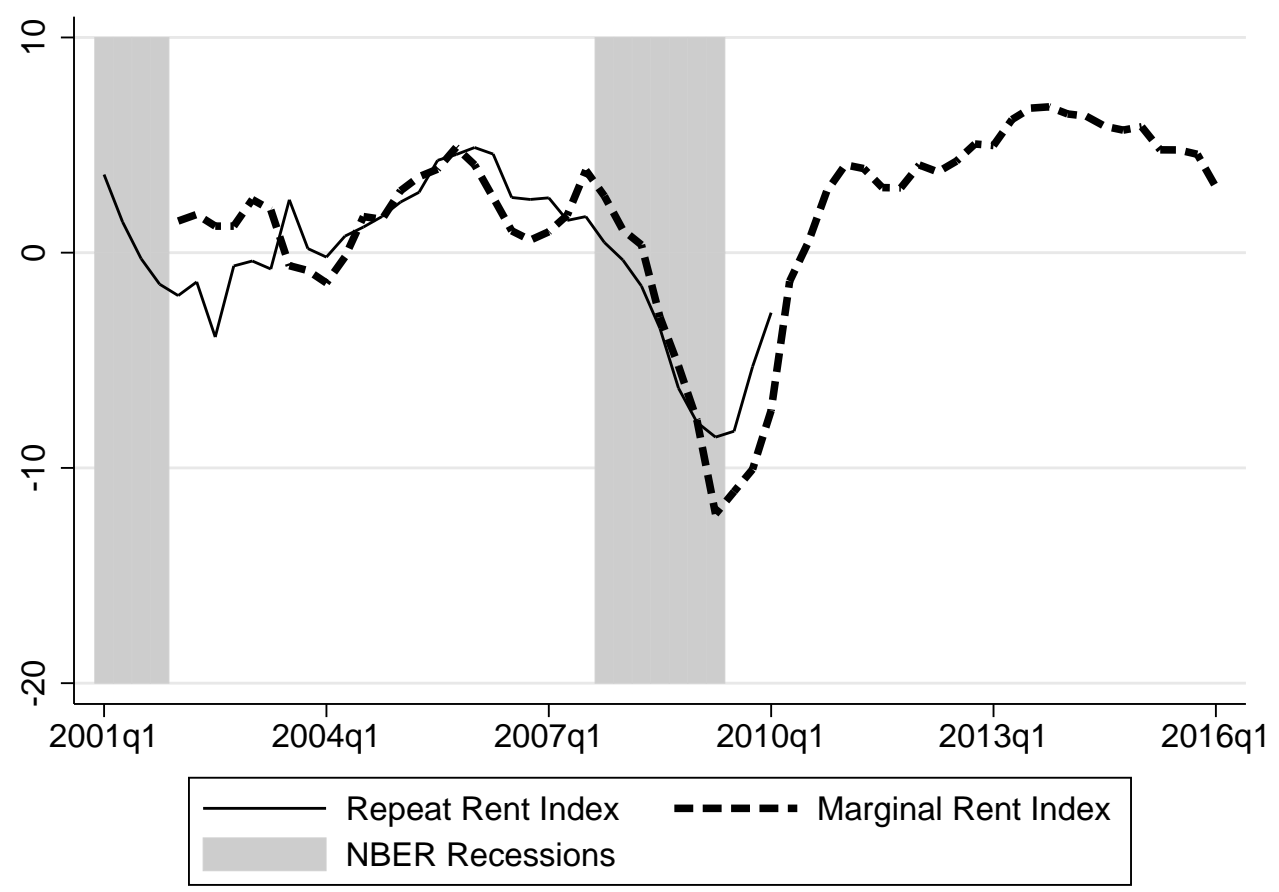

(b) Percentage change from Year Ago

Figure 6: Repeat Rent Index and Marginal Rent Index 


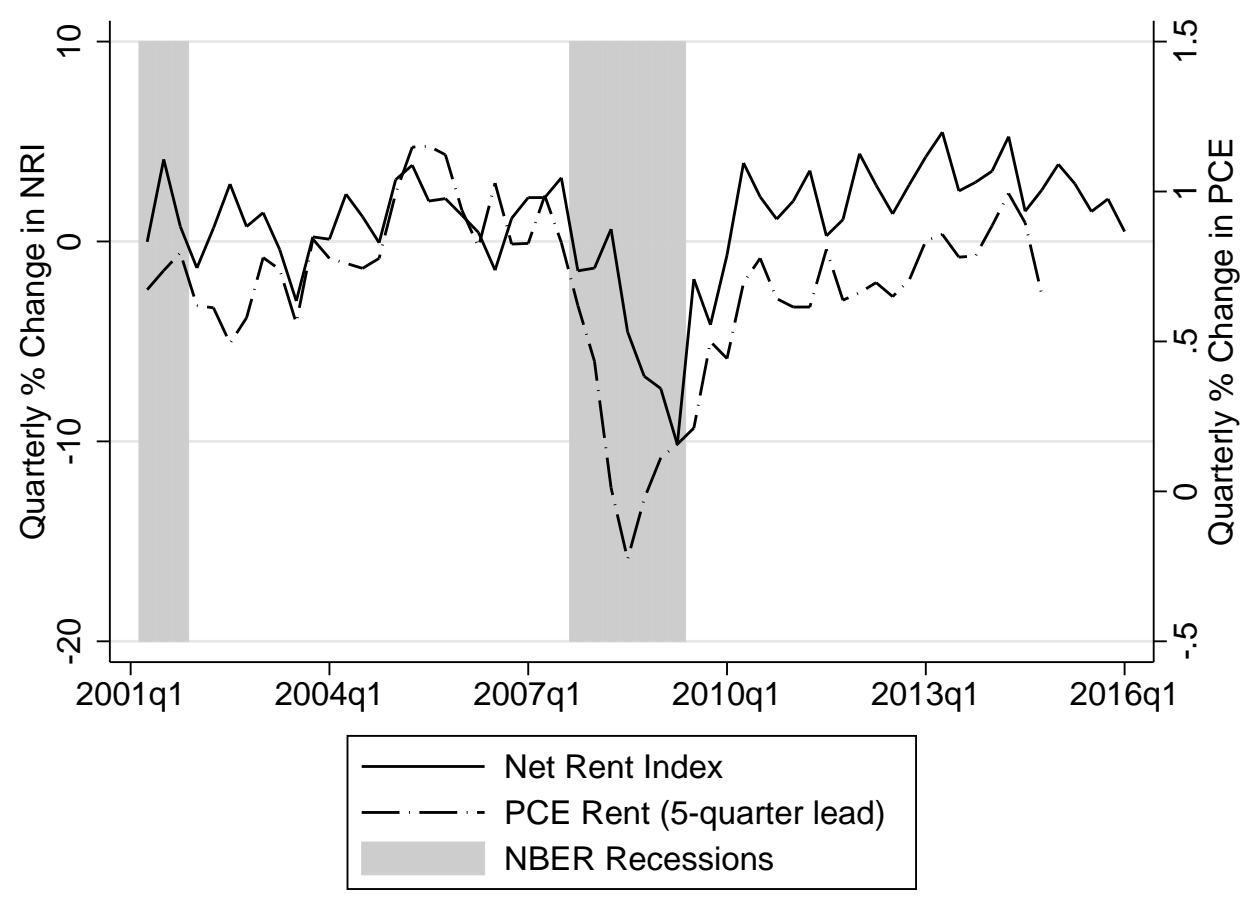

Figure 7: Relation between Net Rent Index and the 5-Quarter Lead PCE Rent

This figure depicts quarterly percentage changes in the 5-quarter lead PCE rent and the Net Rent Index. 


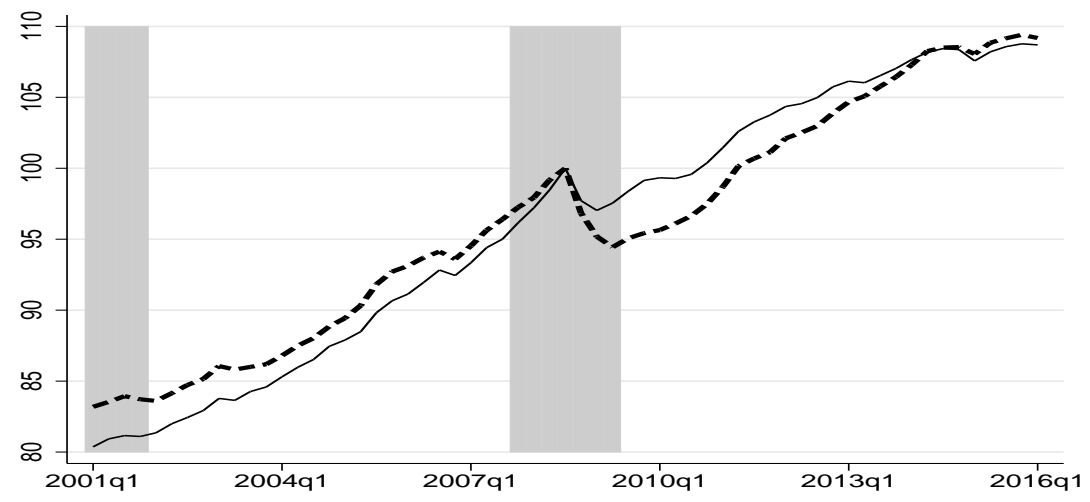

(a) Index Level

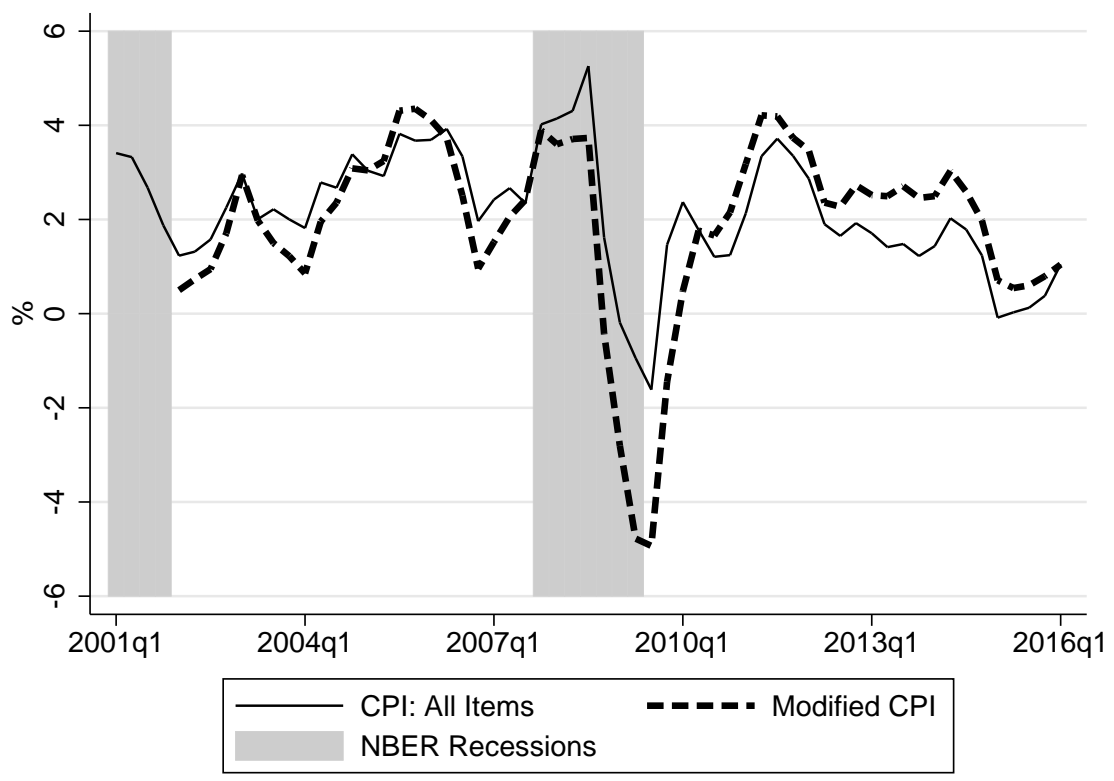

(b) Percentage change from Year Ago

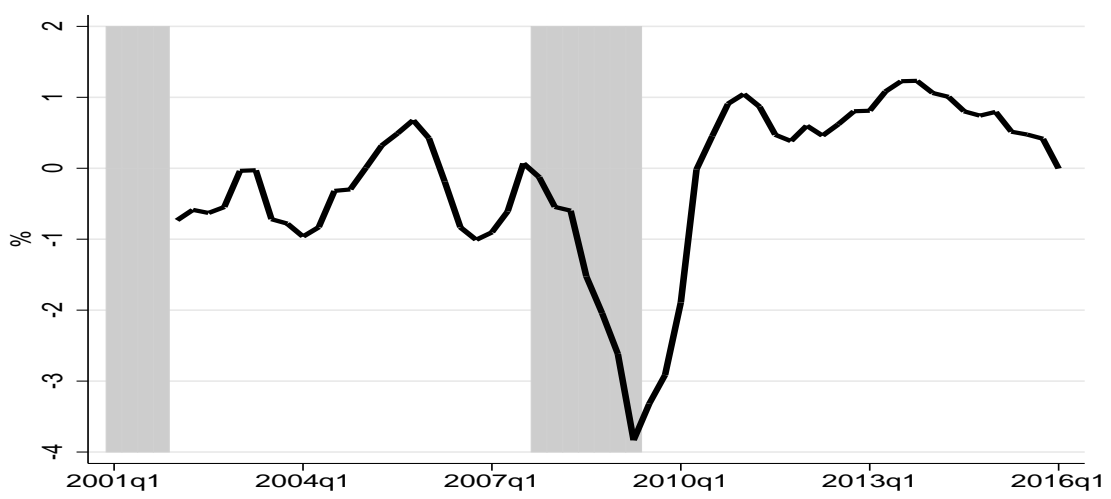

(c) Difference between the Modified and Original CPI

Figure 8: All-Item CPI and Modified CPI 


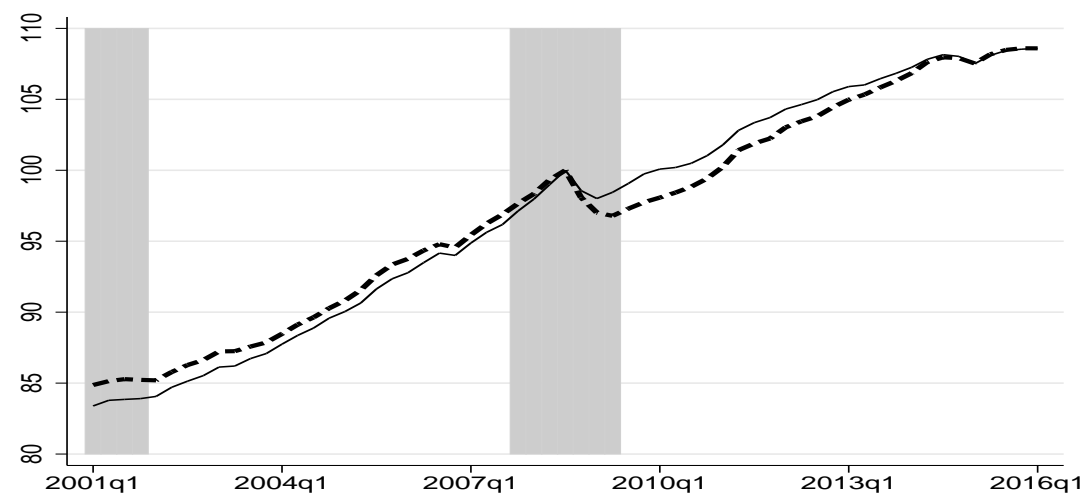

(a) Index Level

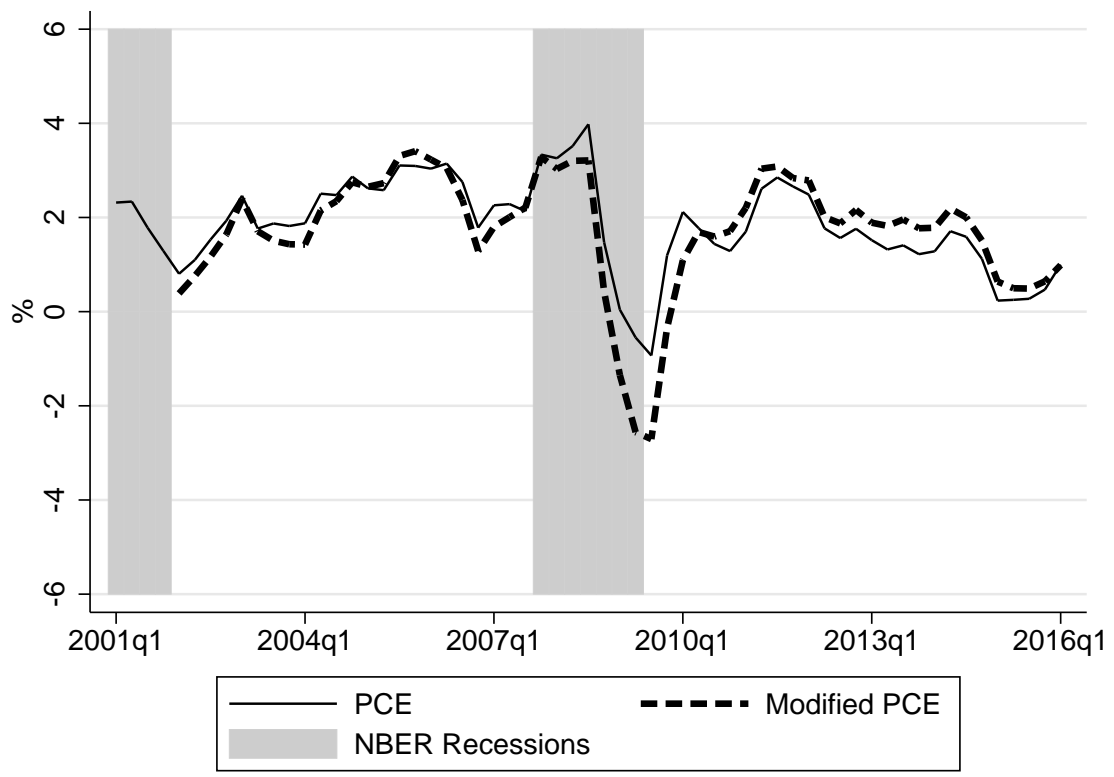

(b) Percentage change from Year Ago

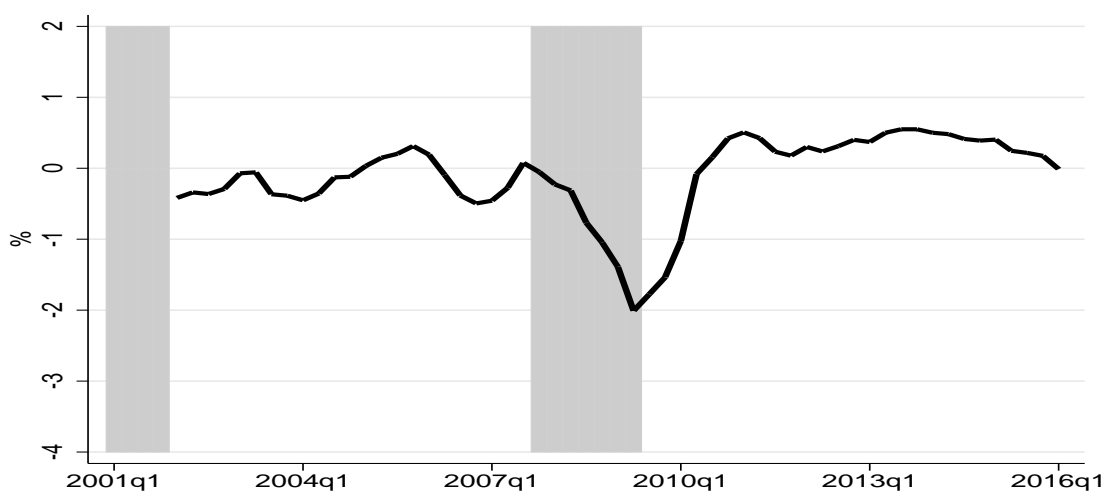

(c) Difference between the Modified and Original PCE

Figure 9: All-Item PCE and Modified PCE Price 


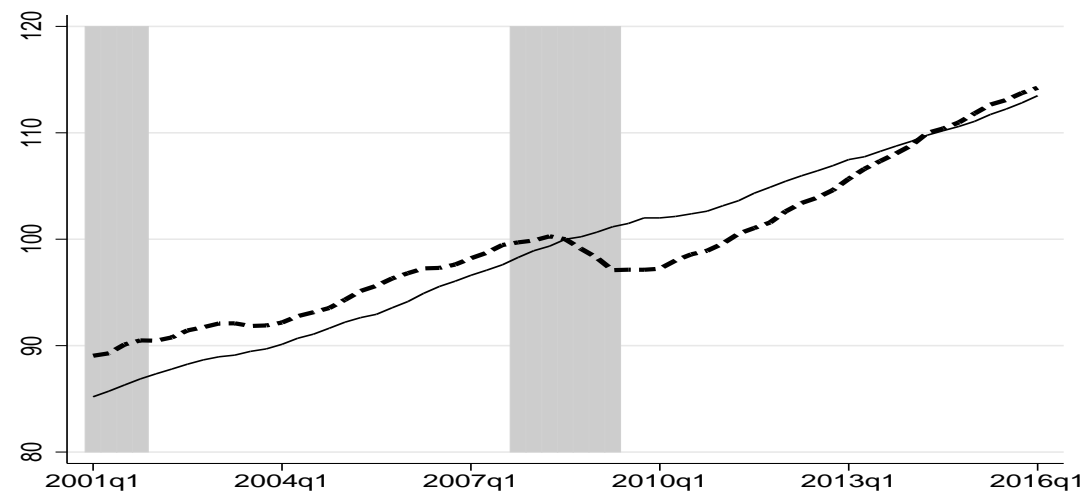

(a) Index Level

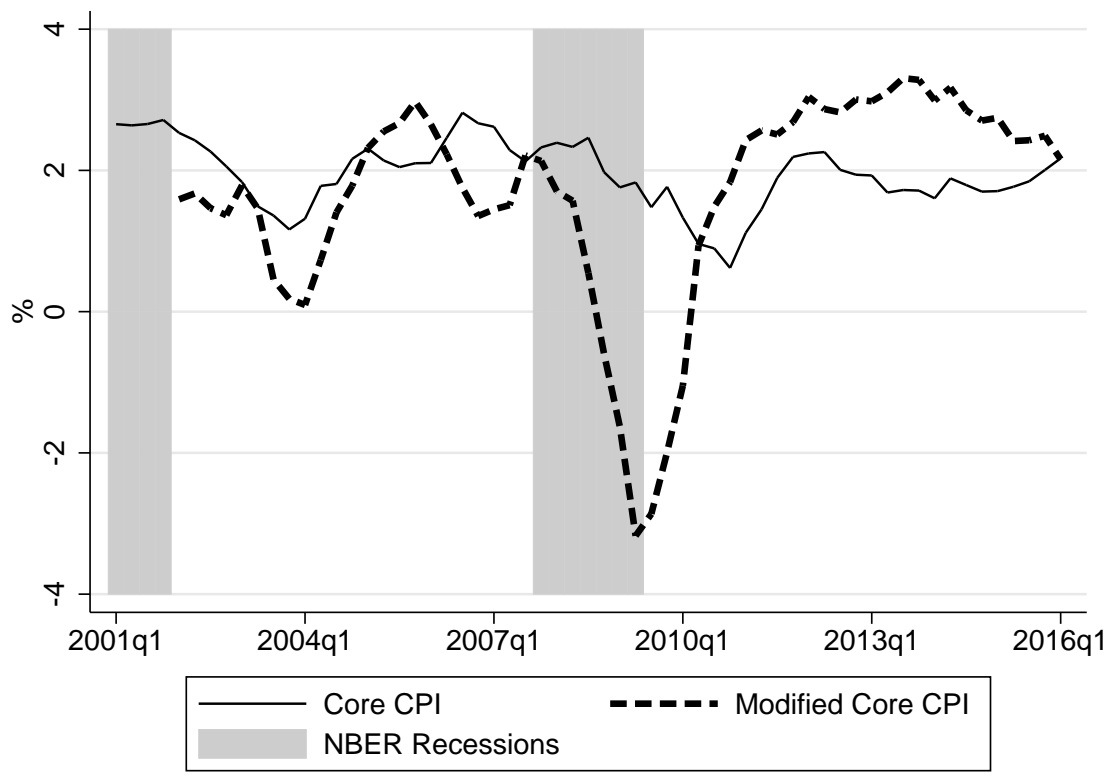

(b) Percentage change from Year Ago

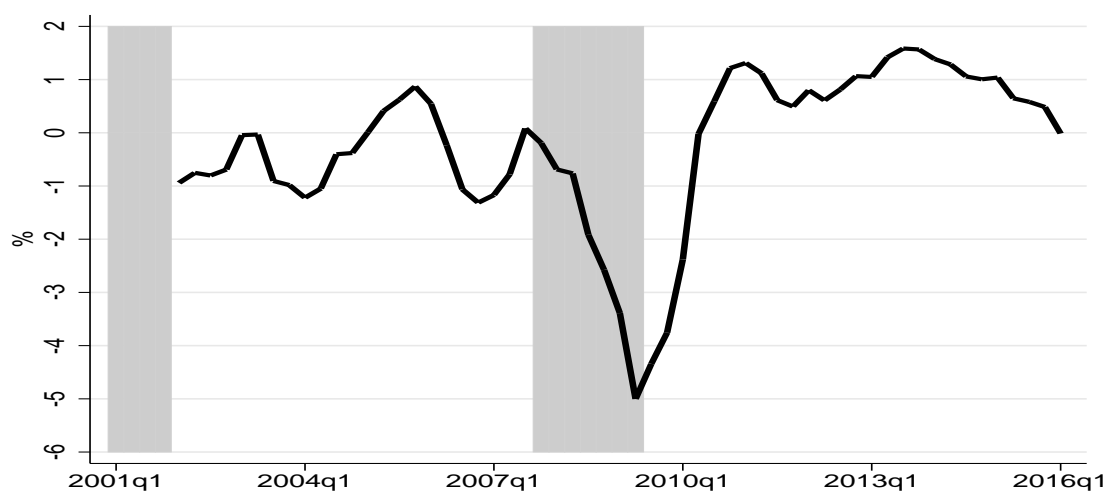

(c) Difference between the Modified and Original Core CPI

Figure 10: Core CPI and Modified Core CPI 


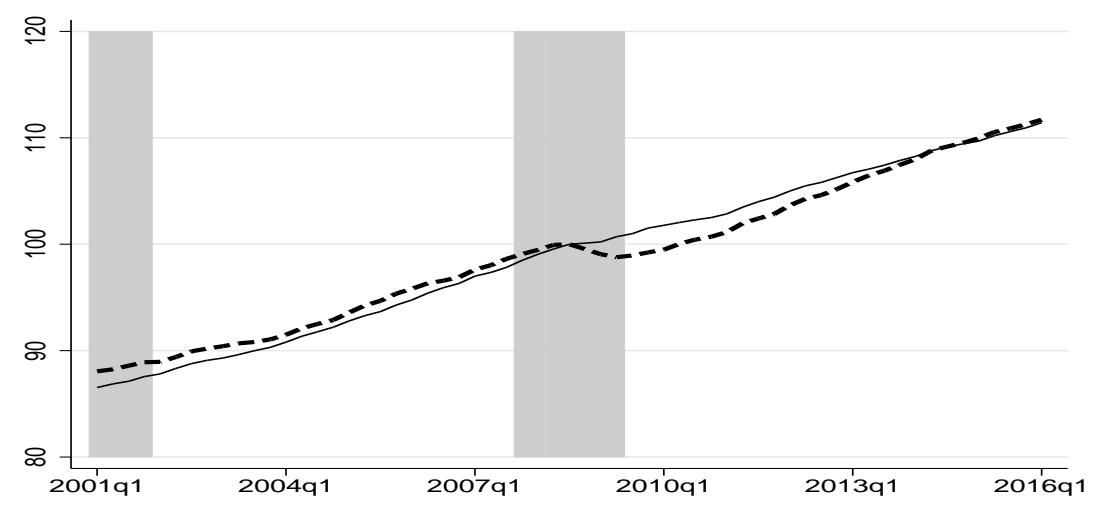

(a) Index Level

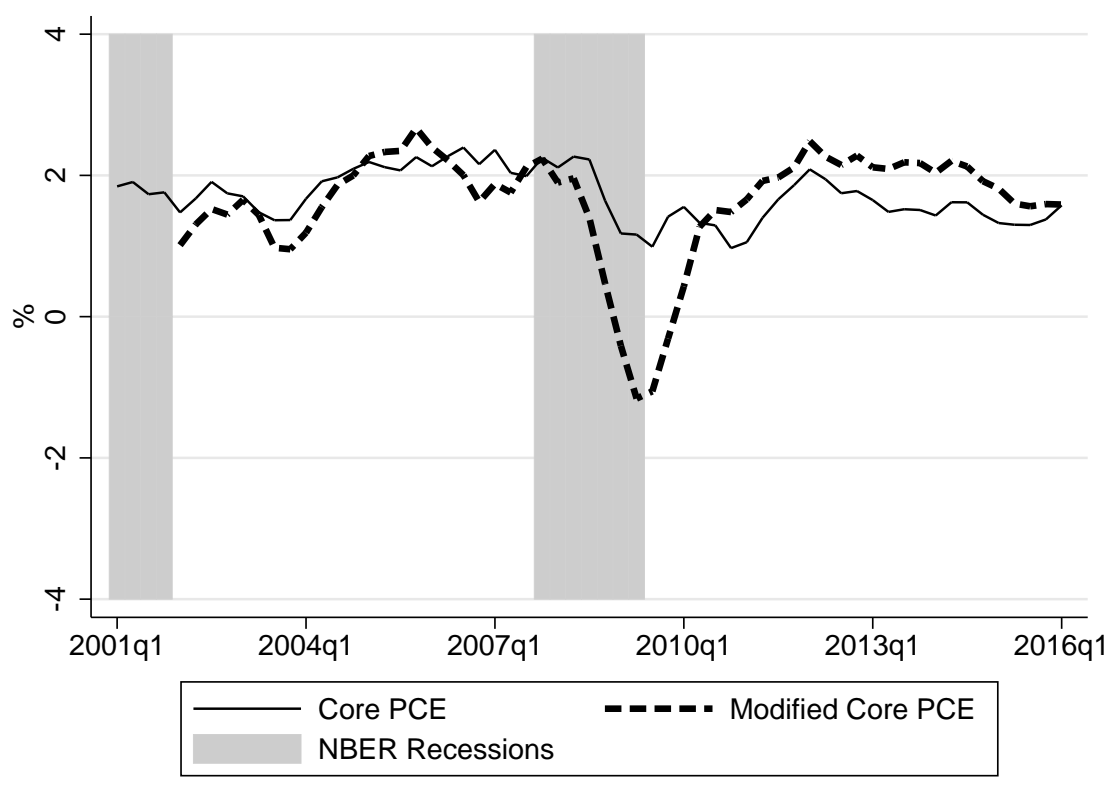

(b) Percentage change from Year Ago

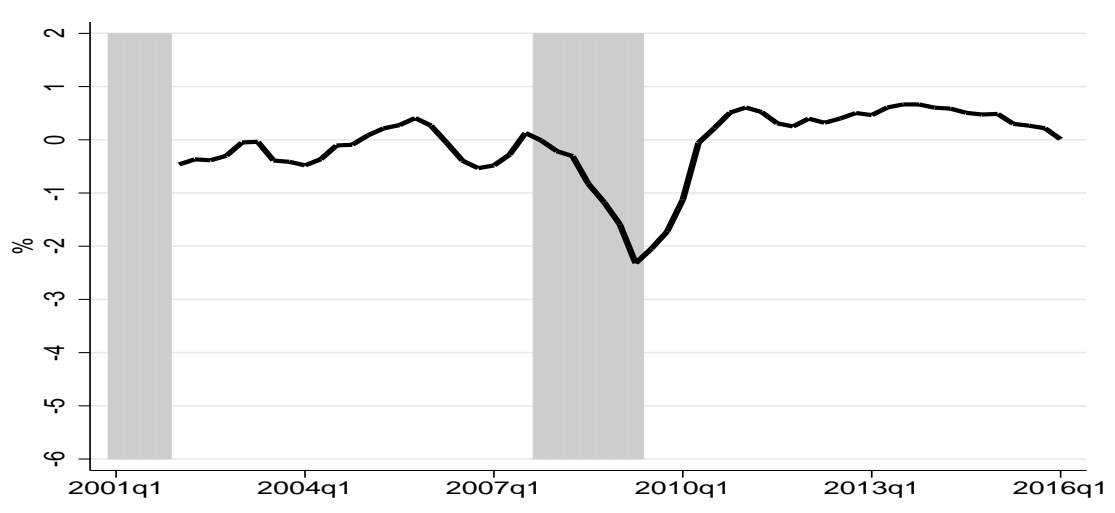

(c) Difference between the Modified and Original Core PCE

Figure 11: Core PCE and Modified Core PCE Price 


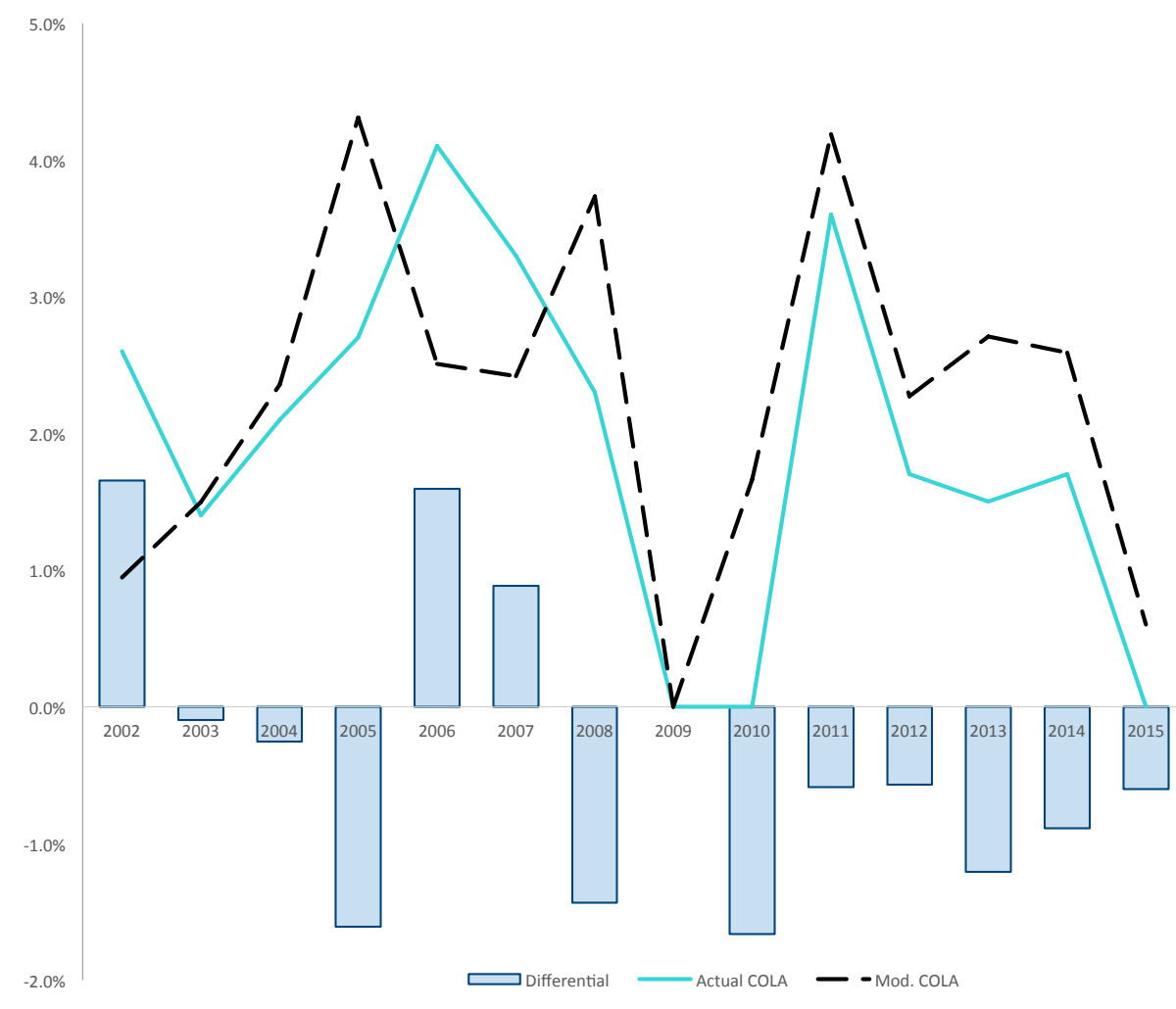

Figure 12: Annual Social Security Cost of Living Increases (COLAs): Actual versus modified 


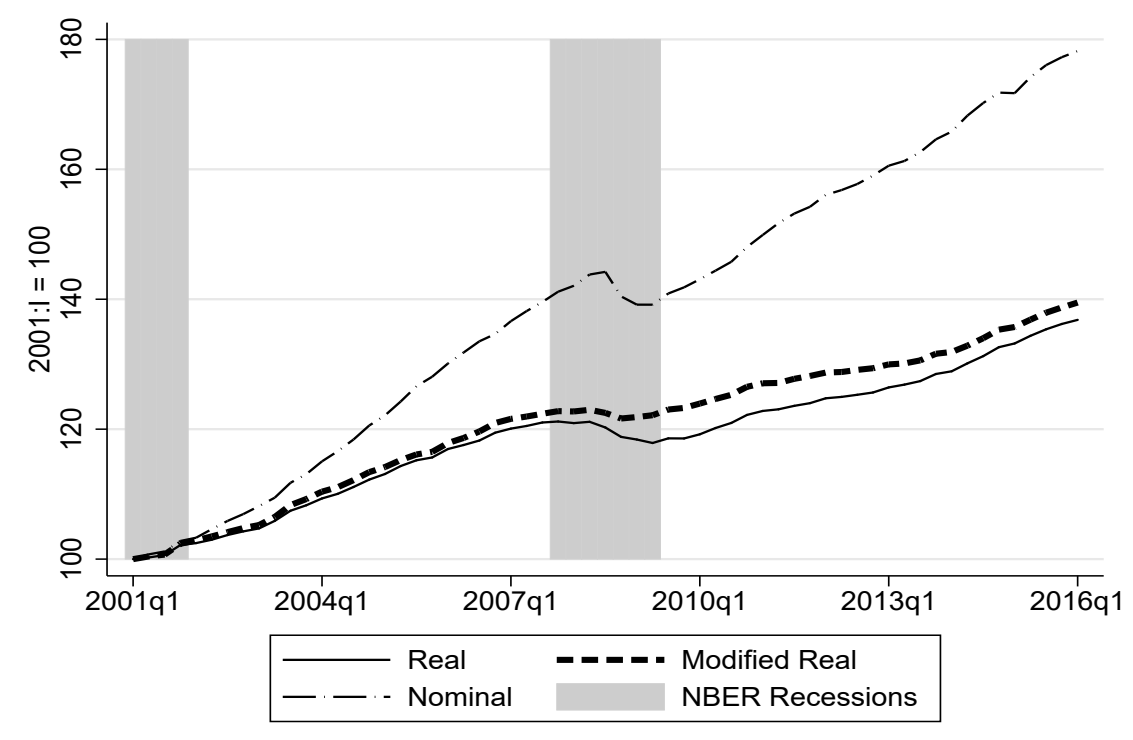

(a) Personal Consumption Expenditures

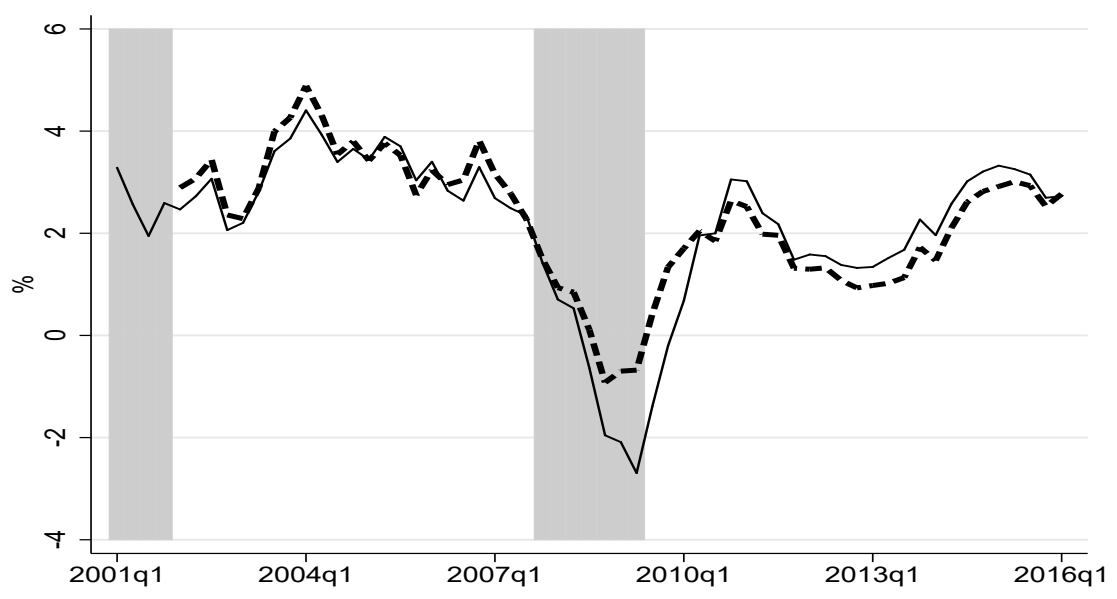

(b) Percentage change from Year Ago

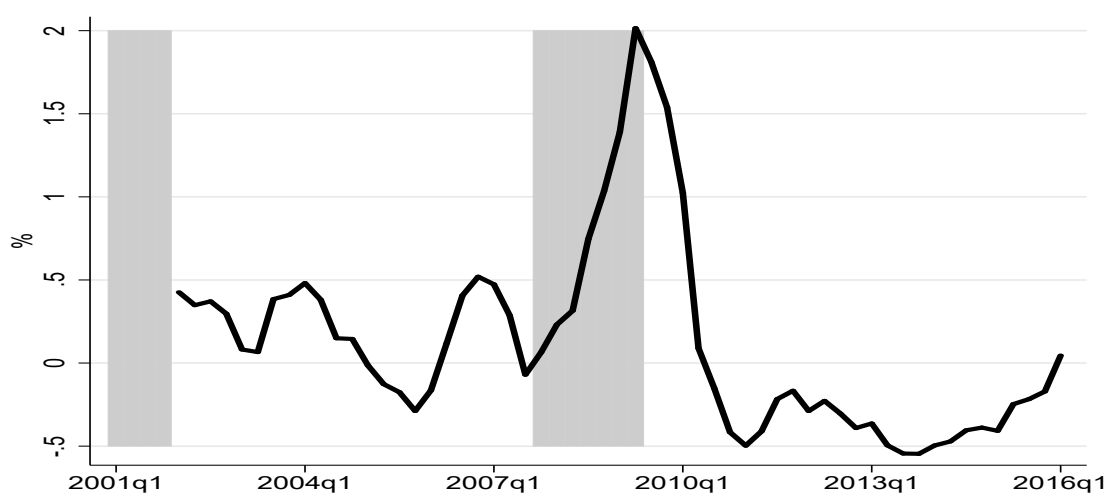

(c) Difference (Modified - Original)

Figure 13: Original and Modified Real Personal Consumption Expenditures 


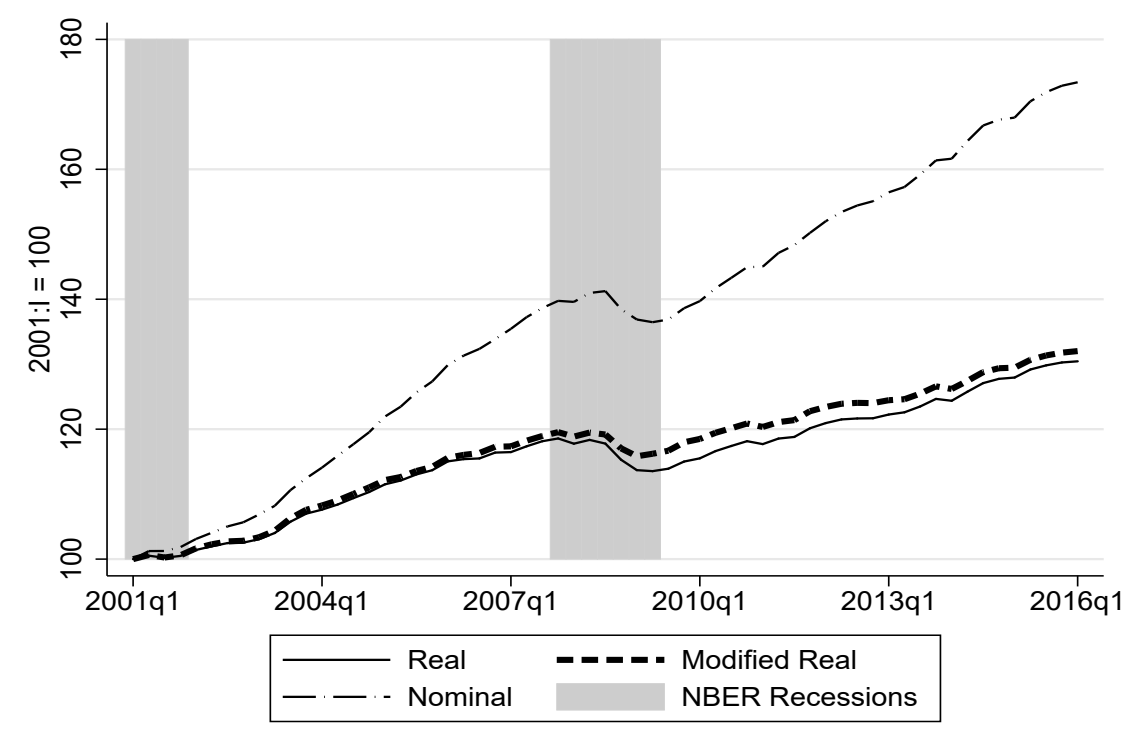

(a) Gross Domestic Product

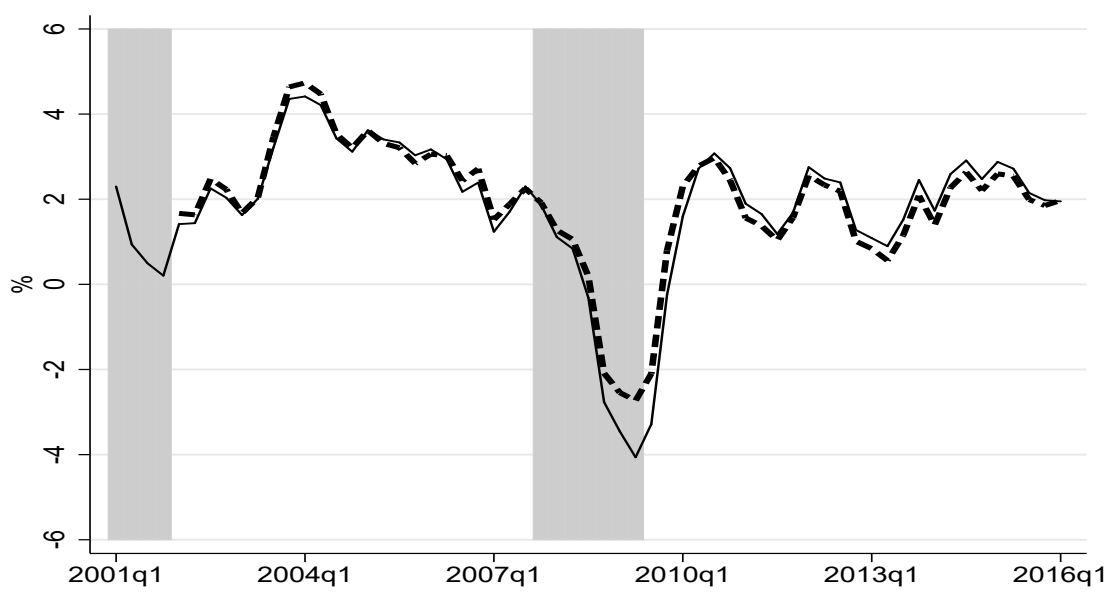

(b) Percentage change from Year Ago

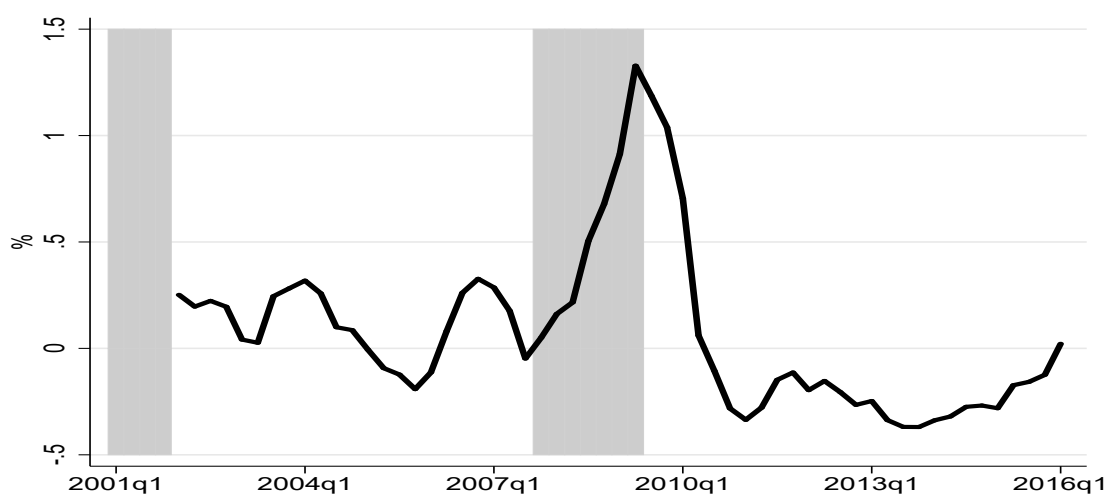

(c) Difference (Modified - Original)

Figure 14: Original and Modified Real Gross Domestic Product 


\section{Appendix A Percentage Change from Year Ago in Con- sumer Price Index}

\begin{tabular}{|c|c|c|c|c|c|c|}
\hline \multirow[b]{2}{*}{ Quarter } & \multicolumn{3}{|c|}{ All-Item } & \multicolumn{3}{|c|}{ Core (excluding food and energy) } \\
\hline & $\begin{array}{l}\text { Original } \\
\text { (1) }\end{array}$ & $\begin{array}{c}\text { Modified } \\
\text { (2) }\end{array}$ & $\begin{array}{l}\text { Difference } \\
(3)=(2)-(1)\end{array}$ & $\begin{array}{l}\text { Original } \\
(4)\end{array}$ & $\begin{array}{l}\text { Modified } \\
\quad(5)\end{array}$ & $\begin{array}{l}\text { Difference } \\
(6)=(5)-(4)\end{array}$ \\
\hline $2002 q 1$ & 1.232 & 0.498 & -0.734 & 2.532 & 1.59 & -0.942 \\
\hline $2002 q 2$ & 1.317 & 0.731 & -0.586 & 2.426 & 1.674 & -0.752 \\
\hline $2002 q 3$ & 1.576 & 0.946 & -0.63 & 2.267 & 1.465 & -0.803 \\
\hline $2002 q 4$ & 2.254 & 1.707 & -0.546 & 2.057 & 1.366 & -0.691 \\
\hline $2003 q 1$ & 2.976 & 2.94 & -0.036 & 1.834 & 1.79 & -0.044 \\
\hline $2003 q 2$ & 2.006 & 1.978 & -0.027 & 1.491 & 1.459 & -0.032 \\
\hline $2003 q 3$ & 2.217 & 1.499 & -0.718 & 1.361 & 0.456 & -0.905 \\
\hline $2003 q 4$ & 2.002 & 1.222 & -0.78 & 1.164 & 0.182 & -0.982 \\
\hline $2004 q 1$ & 1.818 & 0.855 & -0.963 & 1.316 & 0.095 & -1.221 \\
\hline $2004 q 2$ & 2.786 & 1.955 & -0.831 & 1.781 & 0.731 & -1.049 \\
\hline $2004 q 3$ & 2.675 & 2.356 & -0.318 & 1.808 & 1.405 & -0.403 \\
\hline $2004 q 4$ & 3.385 & 3.086 & -0.299 & 2.164 & 1.784 & -0.38 \\
\hline $2005 q 1$ & 3.035 & 3.043 & 0.008 & 2.308 & 2.318 & 0.01 \\
\hline $2005 q 2$ & 2.923 & 3.243 & 0.32 & 2.14 & 2.552 & 0.412 \\
\hline $2005 q 3$ & 3.82 & 4.31 & 0.491 & 2.047 & 2.67 & 0.624 \\
\hline $2005 q 4$ & 3.675 & 4.353 & 0.678 & 2.102 & 2.974 & 0.872 \\
\hline $2006 q 1$ & 3.691 & 4.114 & 0.423 & 2.105 & 2.651 & 0.546 \\
\hline $2006 q 2$ & 3.924 & 3.736 & -0.188 & 2.461 & 2.228 & -0.233 \\
\hline $2006 q 3$ & 3.34 & 2.508 & -0.833 & 2.818 & 1.754 & -1.064 \\
\hline $2006 q 4$ & 1.965 & 0.956 & -1.009 & 2.668 & 1.354 & -1.314 \\
\hline $2007 q 1$ & 2.423 & 1.52 & -0.903 & 2.618 & 1.449 & -1.17 \\
\hline
\end{tabular}




\begin{tabular}{|c|c|c|c|c|c|c|}
\hline \multirow[b]{2}{*}{ Quarter } & \multicolumn{3}{|c|}{ All-Item } & \multicolumn{3}{|c|}{ Core (excluding food and energy) } \\
\hline & $\begin{array}{l}\text { Original } \\
\text { (1) }\end{array}$ & $\begin{array}{l}\text { Modified } \\
\text { (2) }\end{array}$ & $\begin{array}{l}\text { Difference } \\
(3)=(2)-(1)\end{array}$ & $\begin{array}{l}\text { Original } \\
\text { (4) }\end{array}$ & $\begin{array}{l}\text { Modified } \\
\text { (5) }\end{array}$ & $\begin{array}{l}\text { Difference } \\
(6)=(5)-(4)\end{array}$ \\
\hline $2007 q 2$ & 2.666 & 2.058 & -0.608 & 2.289 & 1.508 & -0.78 \\
\hline $2007 q 3$ & 2.346 & 2.416 & 0.07 & 2.128 & 2.212 & 0.084 \\
\hline $2007 q 4$ & 4.02 & 3.894 & -0.126 & 2.326 & 2.134 & -0.192 \\
\hline $2008 q 1$ & 4.144 & 3.599 & -0.545 & 2.392 & 1.704 & -0.688 \\
\hline $2008 \mathrm{q} 2$ & 4.307 & 3.71 & -0.597 & 2.333 & 1.571 & -0.762 \\
\hline $2008 \mathrm{q} 3$ & 5.258 & 3.733 & -1.525 & 2.463 & 0.547 & -1.916 \\
\hline $2008 q 4$ & 1.615 & -0.427 & -2.042 & 1.975 & -0.602 & -2.576 \\
\hline $2009 \mathrm{q} 1$ & -0.188 & -2.805 & -2.617 & 1.76 & -1.629 & -3.389 \\
\hline $2009 q 2$ & -0.943 & -4.777 & -3.834 & 1.83 & -3.174 & -5.004 \\
\hline $2009 q 3$ & -1.614 & -4.932 & -3.318 & 1.479 & -2.864 & -4.343 \\
\hline $2009 q 4$ & 1.465 & -1.448 & -2.913 & 1.768 & -1.99 & -3.758 \\
\hline $2010 q 1$ & 2.37 & 0.48 & -1.891 & 1.331 & -1.048 & -2.379 \\
\hline $2010 q 2$ & 1.78 & 1.764 & -0.015 & 0.959 & 0.937 & -0.022 \\
\hline $2010 q 3$ & 1.207 & 1.661 & 0.454 & 0.896 & 1.488 & 0.592 \\
\hline $2010 q 4$ & 1.244 & 2.154 & 0.909 & 0.619 & 1.835 & 1.215 \\
\hline $2011 q 1$ & 2.131 & 3.179 & 1.048 & 1.118 & 2.43 & 1.312 \\
\hline $2011 q 2$ & 3.344 & 4.213 & 0.869 & 1.448 & 2.566 & 1.118 \\
\hline 2011q3 & 3.717 & 4.189 & 0.472 & 1.896 & 2.509 & 0.613 \\
\hline $2011 q 4$ & 3.353 & 3.736 & 0.383 & 2.192 & 2.684 & 0.493 \\
\hline $2012 q 1$ & 2.867 & 3.468 & 0.601 & 2.24 & 3.041 & 0.8 \\
\hline $2012 q 2$ & 1.9 & 2.359 & 0.459 & 2.26 & 2.868 & 0.608 \\
\hline $2012 q 3$ & 1.652 & 2.272 & 0.62 & 2.008 & 2.821 & 0.813 \\
\hline $2012 q 4$ & 1.923 & 2.727 & 0.804 & 1.939 & 3.004 & 1.065 \\
\hline
\end{tabular}




\begin{tabular}{|c|c|c|c|c|c|c|}
\hline \multirow[b]{2}{*}{ Quarter } & \multicolumn{3}{|c|}{ All-Item } & \multicolumn{3}{|c|}{ Core (excluding food and energy) } \\
\hline & $\begin{array}{l}\text { Original } \\
\text { (1) }\end{array}$ & $\begin{array}{c}\text { Modified } \\
\text { (2) }\end{array}$ & $\begin{array}{l}\text { Difference } \\
(3)=(2)-(1)\end{array}$ & $\begin{array}{l}\text { Original } \\
\text { (4) }\end{array}$ & $\begin{array}{c}\text { Modified } \\
(5)\end{array}$ & $\begin{array}{l}\text { Difference } \\
(6)=(5)-(4)\end{array}$ \\
\hline $2013 q 1$ & 1.708 & 2.518 & 0.811 & 1.928 & 2.978 & 1.05 \\
\hline $2013 q 2$ & 1.413 & 2.495 & 1.082 & 1.687 & 3.105 & 1.419 \\
\hline $2013 q 3$ & 1.48 & 2.707 & 1.227 & 1.723 & 3.307 & 1.585 \\
\hline $2013 q 4$ & 1.224 & 2.457 & 1.233 & 1.715 & 3.281 & 1.567 \\
\hline $2014 q 1$ & 1.435 & 2.496 & 1.061 & 1.605 & 2.991 & 1.385 \\
\hline $2014 q 2$ & 2.025 & 3.032 & 1.007 & 1.887 & 3.173 & 1.285 \\
\hline $2014 q 3$ & 1.787 & 2.589 & 0.802 & 1.793 & 2.852 & 1.059 \\
\hline $2014 q 4$ & 1.238 & 1.98 & 0.742 & 1.7 & 2.705 & 1.005 \\
\hline $2015 q 1$ & -0.085 & 0.71 & 0.795 & 1.707 & 2.745 & 1.038 \\
\hline $2015 q 2$ & 0.028 & 0.544 & 0.515 & 1.768 & 2.416 & 0.648 \\
\hline $2015 q 3$ & 0.126 & 0.602 & 0.476 & 1.845 & 2.427 & 0.582 \\
\hline $2015 q 4$ & 0.379 & 0.796 & 0.416 & 2.006 & 2.491 & 0.485 \\
\hline $2016 q 1$ & 1.048 & 1.043 & -0.005 & 2.171 & 2.157 & -0.014 \\
\hline
\end{tabular}

Table 14: Percentage Change from Year Ago in Consumer Price Index 


\section{Appendix B Percentage Change from Year Ago in Per-}

sonal Consumption Expenditures Price In$\operatorname{dex}$

\begin{tabular}{|c|c|c|c|c|c|c|}
\hline \multirow[b]{2}{*}{ Quarter } & \multicolumn{3}{|c|}{ All-Item } & \multicolumn{3}{|c|}{ Core (excluding food and energy) } \\
\hline & $\begin{array}{l}\text { Original } \\
\text { (1) }\end{array}$ & $\begin{array}{c}\text { Modified } \\
\text { (2) }\end{array}$ & $\begin{array}{l}\text { Difference } \\
(3)=(2)-(1)\end{array}$ & $\begin{array}{l}\text { Original } \\
\text { (4) }\end{array}$ & $\begin{array}{c}\text { Modified } \\
(5)\end{array}$ & $\begin{array}{l}\text { Difference } \\
(6)=(5)-(4)\end{array}$ \\
\hline $2002 q 1$ & 0.805 & 0.387 & -0.418 & 1.476 & 1.012 & -0.464 \\
\hline $2002 q 2$ & 1.099 & 0.759 & -0.34 & 1.675 & 1.307 & -0.367 \\
\hline $2002 q 3$ & 1.532 & 1.169 & -0.363 & 1.909 & 1.524 & -0.385 \\
\hline $2002 q 4$ & 1.93 & 1.639 & -0.291 & 1.746 & 1.446 & -0.3 \\
\hline $2003 q 1$ & 2.462 & 2.391 & -0.071 & 1.704 & 1.654 & -0.05 \\
\hline $2003 q 2$ & 1.765 & 1.708 & -0.057 & 1.478 & 1.44 & -0.038 \\
\hline $2003 q 3$ & 1.873 & 1.507 & -0.366 & 1.365 & 0.975 & -0.39 \\
\hline $2003 q 4$ & 1.819 & 1.432 & -0.387 & 1.368 & 0.954 & -0.414 \\
\hline $2004 q 1$ & 1.877 & 1.425 & -0.451 & 1.67 & 1.189 & -0.48 \\
\hline $2004 q 2$ & 2.506 & 2.15 & -0.356 & 1.916 & 1.55 & -0.366 \\
\hline $2004 q 3$ & 2.476 & 2.348 & -0.128 & 1.972 & 1.866 & -0.107 \\
\hline $2004 q 4$ & 2.869 & 2.749 & -0.12 & 2.093 & 1.999 & -0.093 \\
\hline $2005 q 1$ & 2.619 & 2.653 & 0.034 & 2.19 & 2.274 & 0.084 \\
\hline $2005 q 2$ & 2.58 & 2.729 & 0.149 & 2.117 & 2.332 & 0.215 \\
\hline $2005 q 3$ & 3.105 & 3.308 & 0.204 & 2.071 & 2.347 & 0.276 \\
\hline $2005 q 4$ & 3.095 & 3.409 & 0.314 & 2.26 & 2.668 & 0.409 \\
\hline $2006 q 1$ & 3.038 & 3.23 & 0.192 & 2.129 & 2.396 & 0.267 \\
\hline $2006 q 2$ & 3.145 & 3.051 & -0.093 & 2.271 & 2.214 & -0.057 \\
\hline $2006 q 3$ & 2.755 & 2.37 & -0.384 & 2.395 & 2.003 & -0.392 \\
\hline
\end{tabular}




\begin{tabular}{|c|c|c|c|c|c|c|}
\hline \multirow[b]{2}{*}{ Quarter } & \multicolumn{3}{|c|}{ All-Item } & \multicolumn{3}{|c|}{ Core (excluding food and energy) } \\
\hline & $\begin{array}{l}\text { Original } \\
\text { (1) }\end{array}$ & $\begin{array}{l}\text { Modified } \\
\qquad(2)\end{array}$ & $\begin{array}{l}\text { Difference } \\
(3)=(2)-(1)\end{array}$ & $\begin{array}{l}\text { Original } \\
\text { (4) }\end{array}$ & $\begin{array}{l}\text { Modified } \\
\qquad(5)\end{array}$ & $\begin{array}{l}\text { Difference } \\
(6)=(5)-(4)\end{array}$ \\
\hline $2006 q 4$ & 1.784 & 1.288 & -0.496 & 2.158 & 1.625 & -0.533 \\
\hline $2007 q 1$ & 2.259 & 1.802 & -0.457 & 2.362 & 1.88 & -0.482 \\
\hline $2007 q 2$ & 2.284 & 2.008 & -0.276 & 2.037 & 1.758 & -0.279 \\
\hline $2007 q 3$ & 2.134 & 2.211 & 0.076 & 1.99 & 2.119 & 0.129 \\
\hline $2007 q 4$ & 3.335 & 3.283 & -0.052 & 2.248 & 2.237 & -0.011 \\
\hline $2008 q 1$ & 3.259 & 3.032 & -0.227 & 2.112 & 1.899 & -0.214 \\
\hline $2008 q 2$ & 3.516 & 3.204 & -0.313 & 2.266 & 1.959 & -0.307 \\
\hline $2008 q 3$ & 3.981 & 3.212 & -0.769 & 2.226 & 1.397 & -0.828 \\
\hline $2008 q 4$ & 1.472 & 0.428 & -1.045 & 1.641 & 0.468 & -1.173 \\
\hline 2009q1 & 0.042 & -1.347 & -1.389 & 1.178 & -0.412 & -1.59 \\
\hline $2009 q 2$ & -0.549 & -2.559 & -2.01 & 1.162 & -1.159 & -2.321 \\
\hline $2009 q 3$ & -0.931 & -2.706 & -1.775 & 0.99 & -1.057 & -2.048 \\
\hline $2009 q 4$ & 1.195 & -0.341 & -1.537 & 1.416 & -0.31 & -1.726 \\
\hline 2010q1 & 2.117 & 1.092 & -1.025 & 1.554 & 0.428 & -1.126 \\
\hline $2010 q 2$ & 1.776 & 1.693 & -0.083 & 1.329 & 1.272 & -0.056 \\
\hline 2010q3 & 1.439 & 1.595 & 0.156 & 1.293 & 1.51 & 0.217 \\
\hline $2010 q 4$ & 1.287 & 1.709 & 0.422 & 0.971 & 1.481 & 0.51 \\
\hline $2011 q 1$ & 1.699 & 2.205 & 0.506 & 1.054 & 1.661 & 0.606 \\
\hline $2011 q 2$ & 2.611 & 3.037 & 0.426 & 1.4 & 1.922 & 0.523 \\
\hline 2011q3 & 2.85 & 3.084 & 0.233 & 1.661 & 1.97 & 0.309 \\
\hline $2011 q 4$ & 2.66 & 2.837 & 0.178 & 1.861 & 2.112 & 0.251 \\
\hline $2012 q 1$ & 2.486 & 2.787 & 0.301 & 2.086 & 2.484 & 0.398 \\
\hline $2012 q 2$ & 1.77 & 2.007 & 0.237 & 1.946 & 2.265 & 0.32 \\
\hline
\end{tabular}




\begin{tabular}{|c|c|c|c|c|c|c|}
\hline \multirow[b]{2}{*}{ Quarter } & \multicolumn{3}{|c|}{ All-Item } & \multicolumn{3}{|c|}{ Core (excluding food and energy) } \\
\hline & $\begin{array}{l}\text { Original } \\
\text { (1) }\end{array}$ & $\begin{array}{c}\text { Modified } \\
\text { (2) }\end{array}$ & $\begin{array}{l}\text { Difference } \\
(3)=(2)-(1)\end{array}$ & $\begin{array}{l}\text { Original } \\
\text { (4) }\end{array}$ & $\begin{array}{c}\text { Modified } \\
(5)\end{array}$ & $\begin{array}{l}\text { Difference } \\
(6)=(5)-(4)\end{array}$ \\
\hline $2012 q 3$ & 1.564 & 1.876 & 0.311 & 1.748 & 2.148 & 0.4 \\
\hline $2012 q 4$ & 1.761 & 2.161 & 0.4 & 1.779 & 2.282 & 0.503 \\
\hline $2013 q 1$ & 1.519 & 1.889 & 0.37 & 1.65 & 2.115 & 0.465 \\
\hline $2013 q 2$ & 1.321 & 1.821 & 0.501 & 1.483 & 2.091 & 0.608 \\
\hline $2013 q 3$ & 1.409 & 1.958 & 0.55 & 1.521 & 2.186 & 0.665 \\
\hline $2013 q 4$ & 1.221 & 1.771 & 0.55 & 1.51 & 2.175 & 0.665 \\
\hline $2014 q 1$ & 1.282 & 1.782 & 0.5 & 1.432 & 2.036 & 0.604 \\
\hline $2014 q 2$ & 1.708 & 2.19 & 0.481 & 1.62 & 2.206 & 0.586 \\
\hline $2014 q 3$ & 1.59 & 2.003 & 0.413 & 1.619 & 2.126 & 0.507 \\
\hline $2014 q 4$ & 1.122 & 1.512 & 0.39 & 1.443 & 1.918 & 0.475 \\
\hline $2015 q 1$ & 0.235 & 0.639 & 0.404 & 1.326 & 1.812 & 0.487 \\
\hline $2015 q 2$ & 0.252 & 0.498 & 0.246 & 1.302 & 1.602 & 0.3 \\
\hline $2015 q 3$ & 0.273 & 0.49 & 0.217 & 1.298 & 1.563 & 0.265 \\
\hline $2015 q 4$ & 0.469 & 0.644 & 0.175 & 1.377 & 1.594 & 0.218 \\
\hline $2016 q 1$ & 1.001 & 0.988 & -0.012 & 1.577 & 1.588 & 0.011 \\
\hline
\end{tabular}

Table 15: Percentage Change from Year Ago in Personal Consumption Expenditures Price Index 


\section{Appendix C Annualized Quarterly Percentage Change in Real Personal Consumption Expendi- tures and Gross Domestic Products}

\begin{tabular}{|c|c|c|c|c|c|c|}
\hline \multirow[b]{2}{*}{ Quarter } & \multicolumn{3}{|c|}{ Real PCE } & \multicolumn{3}{|c|}{ Real GDP } \\
\hline & $\begin{array}{c}\text { Original } \\
\text { (1) }\end{array}$ & $\begin{array}{c}\text { Modified } \\
\text { (2) }\end{array}$ & $\begin{array}{l}\text { Difference } \\
(3)=(2)-(1)\end{array}$ & $\begin{array}{l}\text { Original } \\
\text { (4) }\end{array}$ & $\begin{array}{c}\text { Modified } \\
(5)\end{array}$ & $\begin{array}{l}\text { Difference } \\
(6)=(5)-(4)\end{array}$ \\
\hline 2001q2 & 1.03 & 1.66 & 0.63 & 2.12 & 2.55 & 0.44 \\
\hline $2001 \mathrm{q} 3$ & 1.46 & 1.12 & -0.34 & -1.27 & -1.55 & -0.28 \\
\hline $2001 q 4$ & 6.11 & 6.62 & 0.51 & 1.11 & 1.32 & 0.21 \\
\hline 2002q1 & 1.20 & 2.08 & 0.88 & 3.68 & 4.32 & 0.64 \\
\hline $2002 \mathrm{q} 2$ & 2.04 & 2.36 & 0.32 & 2.21 & 2.42 & 0.22 \\
\hline 2002q3 & 2.80 & 2.54 & -0.26 & 1.95 & 1.76 & -0.19 \\
\hline $2002 q 4$ & 2.15 & 2.37 & 0.22 & 0.25 & 0.36 & 0.11 \\
\hline 2003q1 & 1.76 & 1.79 & 0.03 & 2.07 & 2.10 & 0.03 \\
\hline $2003 q 2$ & 4.45 & 4.72 & 0.26 & 3.71 & 3.87 & 0.16 \\
\hline $2003 \mathrm{q} 3$ & 5.90 & 6.88 & 0.99 & 6.70 & 7.37 & 0.67 \\
\hline $2003 q 4$ & 3.11 & 3.42 & 0.32 & 4.68 & 4.91 & 0.24 \\
\hline $2004 q 1$ & 3.89 & 4.19 & 0.30 & 2.30 & 2.47 & 0.17 \\
\hline $2004 q 2$ & 2.60 & 2.48 & -0.12 & 2.93 & 2.86 & -0.07 \\
\hline $2004 q 3$ & 3.82 & 3.91 & 0.08 & 3.64 & 3.69 & 0.05 \\
\hline $2004 q 4$ & 4.10 & 4.40 & 0.30 & 3.46 & 3.65 & 0.19 \\
\hline $2005 \mathrm{q} 1$ & 3.06 & 2.74 & -0.32 & 4.26 & 4.07 & -0.19 \\
\hline $2005 q 2$ & 4.35 & 3.79 & -0.56 & 2.09 & 1.68 & -0.41 \\
\hline $2005 q 3$ & 3.10 & 2.99 & -0.11 & 3.36 & 3.30 & -0.07 \\
\hline $2005 q 4$ & 1.51 & 1.36 & -0.15 & 2.28 & 2.20 & -0.08 \\
\hline
\end{tabular}




\begin{tabular}{|c|c|c|c|c|c|c|}
\hline \multirow[b]{2}{*}{ Quarter } & \multicolumn{3}{|c|}{ Real PCE } & \multicolumn{3}{|c|}{ Real GDP } \\
\hline & $\begin{array}{l}\text { Original } \\
\text { (1) }\end{array}$ & $\begin{array}{c}\text { Modified } \\
\text { (2) }\end{array}$ & $\begin{array}{l}\text { Difference } \\
(3)=(2)-(1)\end{array}$ & $\begin{array}{l}\text { Original } \\
\text { (4) }\end{array}$ & $\begin{array}{c}\text { Modified } \\
(5)\end{array}$ & $\begin{array}{l}\text { Difference } \\
(6)=(5)-(4)\end{array}$ \\
\hline $2006 q 1$ & 4.49 & 4.66 & 0.17 & 4.81 & 4.92 & 0.12 \\
\hline $2006 q 2$ & 2.13 & 2.68 & 0.55 & 1.20 & 1.54 & 0.35 \\
\hline $2006 q 3$ & 2.34 & 3.35 & 1.01 & 0.36 & 0.99 & 0.64 \\
\hline $2006 q 4$ & 4.08 & 4.36 & 0.29 & 3.13 & 3.31 & 0.17 \\
\hline $2007 q 1$ & 2.10 & 2.11 & 0.00 & 0.25 & 0.22 & -0.03 \\
\hline $2007 q 2$ & 1.36 & 1.19 & -0.17 & 3.06 & 2.97 & -0.09 \\
\hline $2007 q 3$ & 1.78 & 1.39 & -0.39 & 2.69 & 2.45 & -0.25 \\
\hline $2007 q 4$ & 0.50 & 1.31 & 0.81 & 1.43 & 1.99 & 0.56 \\
\hline $2008 q 1$ & -0.83 & -0.16 & 0.66 & -2.73 & -2.32 & 0.41 \\
\hline $2008 \mathrm{q} 2$ & 0.67 & 0.84 & 0.16 & 1.99 & 2.11 & 0.13 \\
\hline $2008 \mathrm{q} 3$ & -2.89 & -1.54 & 1.35 & -1.92 & -1.00 & 0.92 \\
\hline $2008 \mathrm{q} 4$ & -4.81 & -2.81 & 2.00 & -8.45 & -7.16 & 1.29 \\
\hline 2009q1 & -1.37 & 0.73 & 2.10 & -5.54 & -4.16 & 1.38 \\
\hline $2009 q 2$ & -1.80 & 0.92 & 2.72 & -0.54 & 1.33 & 1.87 \\
\hline $2009 q 3$ & 2.43 & 2.87 & 0.44 & 1.31 & 1.61 & 0.30 \\
\hline $2009 q 4$ & -0.04 & 0.81 & 0.86 & 3.87 & 4.46 & 0.59 \\
\hline $2010 q 1$ & 2.15 & 2.17 & 0.03 & 1.73 & 1.75 & 0.02 \\
\hline $2010 q 2$ & 3.25 & 2.27 & -0.98 & 3.86 & 3.20 & -0.67 \\
\hline $2010 q 3$ & 2.59 & 2.08 & -0.51 & 2.70 & 2.36 & -0.35 \\
\hline $2010 q 4$ & 4.09 & 3.93 & -0.17 & 2.52 & 2.41 & -0.11 \\
\hline $2011 q 1$ & 2.01 & 1.72 & -0.29 & -1.54 & -1.74 & -0.20 \\
\hline $2011 q 2$ & 0.81 & 0.16 & -0.65 & 2.91 & 2.47 & -0.44 \\
\hline $2011 \mathrm{q} 3$ & 1.74 & 1.99 & 0.25 & 0.84 & 1.01 & 0.17 \\
\hline
\end{tabular}




\begin{tabular}{|c|c|c|c|c|c|c|}
\hline \multirow[b]{2}{*}{ Quarter } & \multicolumn{3}{|c|}{ Real PCE } & \multicolumn{3}{|c|}{ Real GDP } \\
\hline & $\begin{array}{l}\text { Original } \\
\text { (1) }\end{array}$ & $\begin{array}{c}\text { Modified } \\
\text { (2) }\end{array}$ & $\begin{array}{l}\text { Difference } \\
(3)=(2)-(1)\end{array}$ & $\begin{array}{l}\text { Original } \\
\text { (4) }\end{array}$ & $\begin{array}{c}\text { Modified } \\
(5)\end{array}$ & $\begin{array}{l}\text { Difference } \\
(6)=(5)-(4)\end{array}$ \\
\hline $2011 q 4$ & 1.35 & 1.37 & 0.03 & 4.51 & 4.53 & 0.03 \\
\hline $2012 q 1$ & 2.41 & 1.64 & -0.77 & 2.65 & 2.13 & -0.52 \\
\hline $2012 q 2$ & 0.68 & 0.27 & -0.41 & 1.87 & 1.59 & -0.27 \\
\hline $2012 q 3$ & 1.06 & 1.01 & -0.05 & 0.48 & 0.44 & -0.04 \\
\hline $2012 q 4$ & 1.12 & 0.79 & -0.32 & 0.09 & -0.13 & -0.22 \\
\hline $2013 q 1$ & 2.49 & 1.83 & -0.66 & 1.90 & 1.45 & -0.45 \\
\hline $2013 q 2$ & 1.37 & 0.44 & -0.93 & 1.11 & 0.48 & -0.63 \\
\hline $2013 q 3$ & 1.69 & 1.45 & -0.24 & 2.95 & 2.79 & -0.16 \\
\hline $2013 q 4$ & 3.45 & 3.13 & -0.32 & 3.77 & 3.55 & -0.21 \\
\hline $2014 q 1$ & 1.28 & 0.82 & -0.47 & -0.93 & -1.26 & -0.33 \\
\hline $2014 q 2$ & 3.79 & 2.96 & -0.83 & 4.49 & 3.94 & -0.56 \\
\hline $2014 q 3$ & 3.41 & 3.44 & 0.03 & 4.21 & 4.24 & 0.03 \\
\hline $2014 q 4$ & 4.20 & 3.95 & -0.25 & 2.06 & 1.86 & -0.19 \\
\hline $2015 q 1$ & 1.74 & 1.20 & -0.54 & 0.64 & 0.26 & -0.38 \\
\hline $2015 q 2$ & 3.53 & 3.33 & -0.20 & 3.86 & 3.73 & -0.13 \\
\hline $2015 q 3$ & 2.99 & 3.13 & 0.14 & 1.97 & 2.06 & 0.09 \\
\hline $2015 q 4$ & 2.43 & 2.35 & -0.08 & 1.38 & 1.32 & -0.06 \\
\hline $2016 q 1$ & 1.85 & 2.16 & 0.30 & 0.54 & 0.73 & 0.19 \\
\hline
\end{tabular}

Table 16: Annualized Quarterly Percentage Change in Real Personal Consumption Expenditures and Real Gross Domestic Product 